ARTICLE

DOI: $10.1038 / s 41467-018-07440-2$

\title{
Multi-inch single-crystalline perovskite membrane for high-detectivity flexible photosensors
}

Yucheng Liu (1) 1, Yunxia Zhang ${ }^{1}$, Zhou Yang ${ }^{1}$, Haochen Ye ${ }^{1}$, Jiangshan Feng ${ }^{1}$, Zhuo Xu1, Xu Zhang ${ }^{2}$,

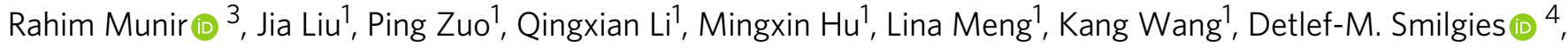

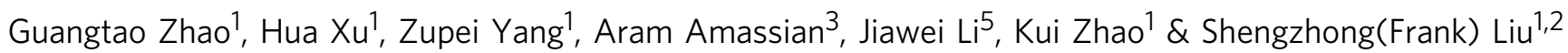

Single crystalline perovskites exhibit high optical absorption, long carrier lifetime, large carrier mobility, low trap-state-density and high defect tolerance. Unfortunately, all single crystalline perovskites attained so far are limited to bulk single crystals and small area wafers. As such, it is impossible to design highly demanded flexible single-crystalline electronics and wearable devices including displays, touch sensing devices, transistors, etc. Herein we report a method of induced peripheral crystallization to prepare large area flexible single-crystalline membrane (SCM) of phenylethylamine lead iodide $\left(\mathrm{C}_{6} \mathrm{H}_{5} \mathrm{C}_{2} \mathrm{H}_{4} \mathrm{NH}_{3}\right)_{2} \mathrm{Pbl}_{4}$ with area exceeding $2500 \mathrm{~mm}^{2}$ and thinness as little as $0.6 \mu \mathrm{m}$. The ultrathin flexible SCM exhibits ultralow defect density, superior uniformity and long-term stability. Using the superior ultrathin membrane, a series of flexible photosensors were designed and fabricated to exhibit very high external quantum efficiency of $26530 \%$, responsivity of $98.17 \mathrm{~A} \mathrm{~W}^{-1}$ and detectivity as much as $1.62 \times 10^{15} \mathrm{~cm} \mathrm{~Hz}^{1 / 2} \mathrm{~W}^{-1}$ (Jones).

\footnotetext{
${ }^{1}$ Key Laboratory of Applied Surface and Colloid Chemistry, Ministry of Education; Shaanxi Key Laboratory for Advanced Energy Devices; Shaanxi Engineering Lab for Advanced Energy Technology; Institute for Advanced Energy Materials; School of Materials Science and Engineering, Shaanxi Normal University, 710119 Xi'an, P. R. China. ${ }^{2}$ iChEM, Dalian National Laboratory for Clean Energy, Dalian Institute of Chemical Physics, Chinese Academy of Sciences, 116023 Dalian, P. R. China. ${ }^{3}$ Division of Physical Sciences and Engineering, Solar and Photovoltaics Engineering Center, King Abdullah University of Science and Technology (KAUST), Thuwal 23955-6900, Saudi Arabia. ${ }^{4}$ Cornell High Energy Synchrotron Source, Cornell University, Ithaca, NY 14850, USA. ${ }^{5}$ School of Physics and Information Technology, Shaanxi Normal University, 710119 Xi'an, P. R. China. These authors contributed equally: Yucheng Liu, Yunxia Zhang. Correspondence and requests for materials should be addressed to K.Z. (email: zhaok@snnu.edu.cn) or to S.L. (email: szliu@dicp.ac.cn)
} 
S ingle-crystalline organic-halide-based perovskites have attracted tremendous research in the past few years due to their superior optoelectronic properties, including high optical absorption $^{1-3}$, long carrier lifetime as much as $>260 \mu \mathrm{s}^{4}$, large carrier mobility (approximately 25-100 $\mathrm{cm}^{2} \mathrm{~V}^{-1} \mathrm{~s}^{-1}$ ) comparing to other organic semiconductors $\mathrm{s}^{3,5-7}$, trap-statedensity measured as low as $10^{9}-10^{10} \mathrm{~cm}^{-33,5-7}$, and highexciton diffusion length reported as long as $1 \mathrm{~mm}^{7,8}$. To date, perovskite single crystals reported ${ }^{9}$ have included $\mathrm{MAPbX}_{3}$ $\left(\mathrm{MA}=\mathrm{CH}_{3} \mathrm{NH}_{3}, \mathrm{X}=\mathrm{Cl}, \mathrm{Br}, \mathrm{I}\right)^{3,5-7,10}, \mathrm{MACaI}_{3}{ }^{11}, \mathrm{MASnX}_{3}{ }^{12,13}$, $\mathrm{FAPbX}_{3}\left(\mathrm{FA}=\mathrm{HC}\left(\mathrm{NH}_{2}\right)_{2}, \mathrm{X}=\mathrm{Cl}, \mathrm{Br}, \mathrm{I}\right)^{2,14-16}, \mathrm{FASnX}_{3}{ }^{12,17}, \mathrm{NH}$ $\left(\mathrm{CH}_{3}\right)_{3} \mathrm{SnX}_{3}{ }^{17}, \mathrm{Cs}_{2} \mathrm{PdBr}_{6}{ }^{18}, \mathrm{Cs}_{2} \mathrm{AgBiBX}_{6}{ }^{19,20}, \mathrm{CsPbX}_{3}{ }^{21-24}$, and mixed ion halide perovskites ${ }^{25-29}$. Unfortunately, all crystalline perovskite materials available at present are limited to bulk single crystals and wafers with thickness much larger than submillimeters while their lateral dimensions limited to only subcentimeter beyond a few large crystals reported by our group ${ }^{1-}$ 3,30 . As such, it is impossible to use the bulk single crystals to design highly demanded flexible electronics and wearable devices, such as displays, touch sensing devices, transistors, photosensors, and solar cells. Even though the microcrystalline perovskite thin films may be used in flexible electronic devices, their efficiencies are fairly low ${ }^{31-33}$. Beyond efforts in our group with limited success $^{1,2,30}$, only a couple of papers reported on thin perovskite single crystals. Specifically, a cavitation-triggered asymmetric crystallization strategy has been developed to form approximately $2.3 \times 1.8 \mathrm{~mm}^{2}$ sized $\mathrm{MAPbBr}_{3}$ single-crystalline sheets ${ }^{34}$. The space confined condition has been introduced to grow $6 \times 8 \mathrm{~mm}^{2}$, $5 \times 4 \mathrm{~mm}^{2}$, and approximately $2.8 \times 3.9 \mathrm{~mm}^{2}$ perovskite crystalline thin films ${ }^{35-37}$. However, they are too small to be usable for real device applications. Most recently, a $120 \mathrm{~cm}^{2}$ (approximately $18.5 \times 6.5 \mathrm{~cm}^{2}$ ) films $\mathrm{MAPbBr}_{3}$ was grown, but it is too thick $(0.4 \mathrm{~mm})$ to be flexible $\mathrm{e}^{38}$. It appears to be indeed intrinsically challenged to grow flexible perovskite single-crystalline membrane (SCM).

Recently, two-dimensional (2D) layered lead halide perovskite has come to the spotlight for its superior environmental stability. In fact, it is recognized as a promising candidate for potential commercial applications in solar cells, light-emitting diodes, and other optoelectronics ${ }^{39-50}$. More recently, 2D layered lead halide perovskite, particularly $\left(\mathrm{C}_{6} \mathrm{H}_{5} \mathrm{C}_{2} \mathrm{H}_{4} \mathrm{NH}_{3}\right)_{2} \mathrm{PbX}_{4}\left((\mathrm{PEA})_{2} \mathrm{PbX}_{4}, \mathrm{X}=\right.$ $\mathrm{Cl}, \mathrm{Br}, \mathrm{I})$ compounds, have been rediscovered for their astonishing stability and potential high solar cell efficiency ${ }^{42,51,52}$. However, up to now all research has been limited to the microcrystalline thin films (MCTFs) and nanocrystalline materials. To take full advantage of its structural, optical, and electronic properties, it is imperative to prepare single crystals. Even though a few limited $2 \mathrm{D}$ layered $(\mathrm{PEA})_{2} \mathrm{PbI}_{4}$ single-crystalline perovskites have already been prepared, unfortunately, none of them is large enough for large-area device applications. Moreover, large-area SCM is needed in order to develop larger-scale integrated optoelectronic devices. In fact, so far there are only three reports on the $(\mathrm{PEA})_{2} \mathrm{PbI}_{4}$ single crystals, with dimensions limited to approximately $0.2 \times 0.2,2 \times 1$, and $8.7 \times 3.1 \mathrm{~mm}^{2}$, respectively ${ }^{53-55}$. It is apparent that the inherent nature of random growth to all directions makes it challenging to control membrane thickness while at the meantime large lateral size is demanded.

In this paper, we report a "induced peripheral crystallization" (IPC) method to grow large-area SCM of $\left(\mathrm{C}_{6} \mathrm{H}_{5} \mathrm{C}_{2} \mathrm{H}_{4} \mathrm{NH}_{3}\right)_{2} \mathrm{PbI}_{4}$ $\left((\mathrm{PEA})_{2} \mathrm{PbI}_{4} \mathrm{SCM}\right)$ with well-controlled thinness to approximately $0.6 \mu \mathrm{m}$, while its area expanded to $>2500 \mathrm{~mm}^{2}(73 \times$ $35 \mathrm{~mm}^{2}$ ), much larger than what is reported in literature to the best of our knowledge ${ }^{54,55}$. It is found that the ultrathin singlecrystalline perovskite membrane displays ultralow defect density, long-term stability, and excellent flexibility. Meanwhile, we have designed and fabricated flexible photosensors using the ultrathin large (PEA) $)_{2} \mathrm{PbI}_{4} \mathrm{SCM}$. It is found that the present photosensor shows very high external quantum efficiency (EQE) as much as $26,530 \%$, responsivity $(R)$ as high as $98.17 \mathrm{~A} \mathrm{~W}^{-1}$, and detectivity $\left(D^{*}\right)$ as large as $1.62 \times 10^{15} \mathrm{~cm} \mathrm{~Hz}^{1 / 2} \mathrm{~W}^{-1}$ (Jones). It should be noted that this detectivity value is not only among the highest detectivity reported to date for all single-crystalline and thin-film perovskite photosensors ${ }^{56}$, it is even higher than devices based on the state-of-the-art material including single-crystalline silicon ${ }^{56}$, InGaAs ${ }^{57}, \mathrm{GaAs}^{58}, \mathrm{CdTe}^{59}$, and $\mathrm{GaN}^{60}$. Moreover, the flexible membrane photosensor shows excellent mechanical stability.

\section{Results}

SCM growth. There have been two typical methods developed to grow the hybrid lead halide perovskite $\mathrm{CH}_{3} \mathrm{NH}_{3} \mathrm{PbI}_{3}$ single crystals. The first uses hydrogen iodide acid as the solvent in which the solubility of perovskite increases as temperature rises. By slowly lowering the temperature of the saturated solution, the crystals are harvested ${ }^{7,61}$. In comparison, the second one uses $\gamma$ butyrolactone (GBL) as the solvent in which solubility of the perovskite decreases as temperature rises. The crystals were collected by first preparing a saturated solution and then slowly increases its temperature to enter into the oversaturation zone $\mathrm{e}^{1-3}$.

There are a few key parameters that are known to affect crystal quality and its growth process. In general, the lower the growth rate, the higher the crystalline quality is. The crystal growth is directly controlled by two processes: the first is solute diffusion from the solution to the crystallite surface, and the second is the solute deposition onto the crystallite. The former can be well controlled by regulating solution temperature for the diffusion rate that is well known to change exponentially with the temperature ${ }^{62}$. However, it is difficult to control the solute deposition process. We therefore maintain the process well under the diffusion-controlled region and use relatively low temperature to regulate the diffusion rate, hence the crystal growth rate and quality. On the other hand, it is key to control the growth along the solubility curve for, when it is in the well-oversaturated region, small crystallites form instantly with plenty of defects. When it goes into the unsaturated region, the crystal formed may start to be dissolved into the solution. Only when the solute concentration is controlled just over the solubility curve or slightly oversaturated, the crystallization kinetics allows highquality crystal growth on the already formed crystallite or seed with no extraneous nucleation ${ }^{63}$.

More quantitatively, crystal growth rate is directly proportional to the first-order derivative of solubility and the temperature ramp rate according to the oversaturation model ${ }^{64}$ :

$$
\frac{\mathrm{d} m}{\mathrm{~d} t}=-\frac{1}{2} V \cdot \frac{\mathrm{d} C(T)}{\mathrm{d} T} \frac{\mathrm{d} T}{\mathrm{~d} t}
$$

where $m$ is the mass of the crystal, $C$ the solution concentration, and $V$ the solution volume that changes very little during the entire crystallization process, hence can be treated as a constant. Figure la shows the solubility of $(\mathrm{PEA})_{2} \mathrm{PbI}_{4}$ perovskite in the GBL solvent measured as a function of temperature. It is clear that, in the temperature range of $27-106^{\circ} \mathrm{C}$, the solubility of $(\mathrm{PEA})_{2} \mathrm{PbI}_{4}$ increases with temperature. Based on the solubility data measured in Fig. 1a, its first-order derivative with respect to temperature is calculated and plotted in Fig. 1b. As the solution temperature can be well controlled over time, so is the temperature ramp rate. Once the temperature is set, the solubility derivative is defined based on the curve in Fig. 1b.

To grow single crystals along lateral dimensions while limiting its growth in thickness, it is critical to selectively control its growth rate along different directions. It is found that the best temperature range is $25-80^{\circ} \mathrm{C}$ in which the solubility derivative is 

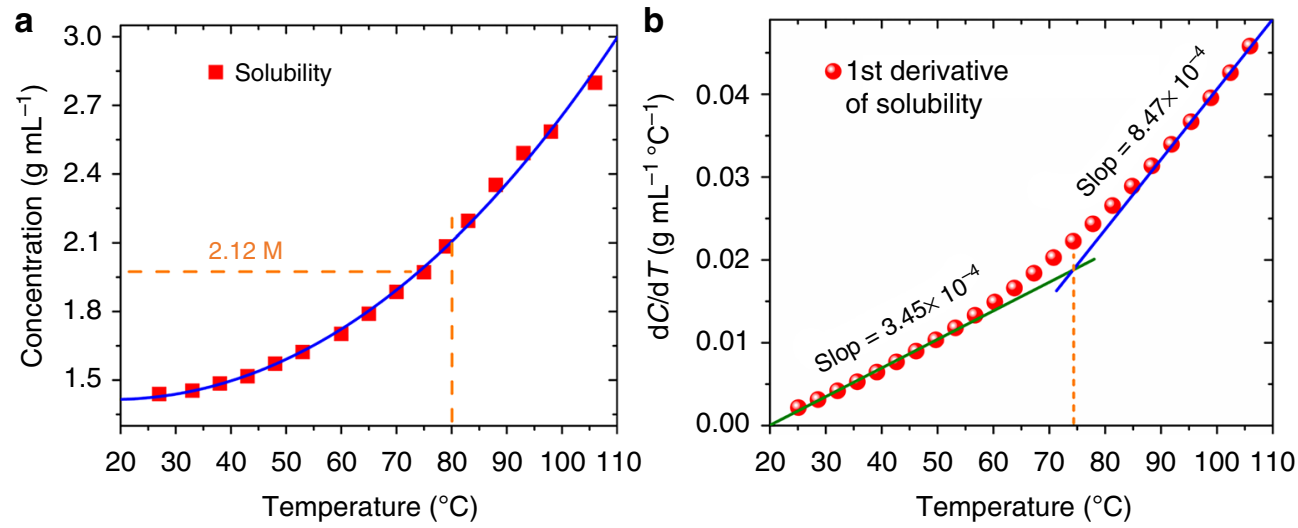

Fig. 1 Temperature-dependent solubility of $(\mathrm{PEA})_{2} \mathrm{Pbl}_{4}$. a Solubility of $(\mathrm{PEA})_{2} \mathrm{Pbl}{ }_{4} \mathrm{SCM}$ in $\mathrm{GBL}$ as a function of temperature. b Solubility derivative with respect to temperature for $(\mathrm{PEA})_{2} \mathrm{Pbl}_{4} \mathrm{SCM}$ in $\mathrm{GBL}$

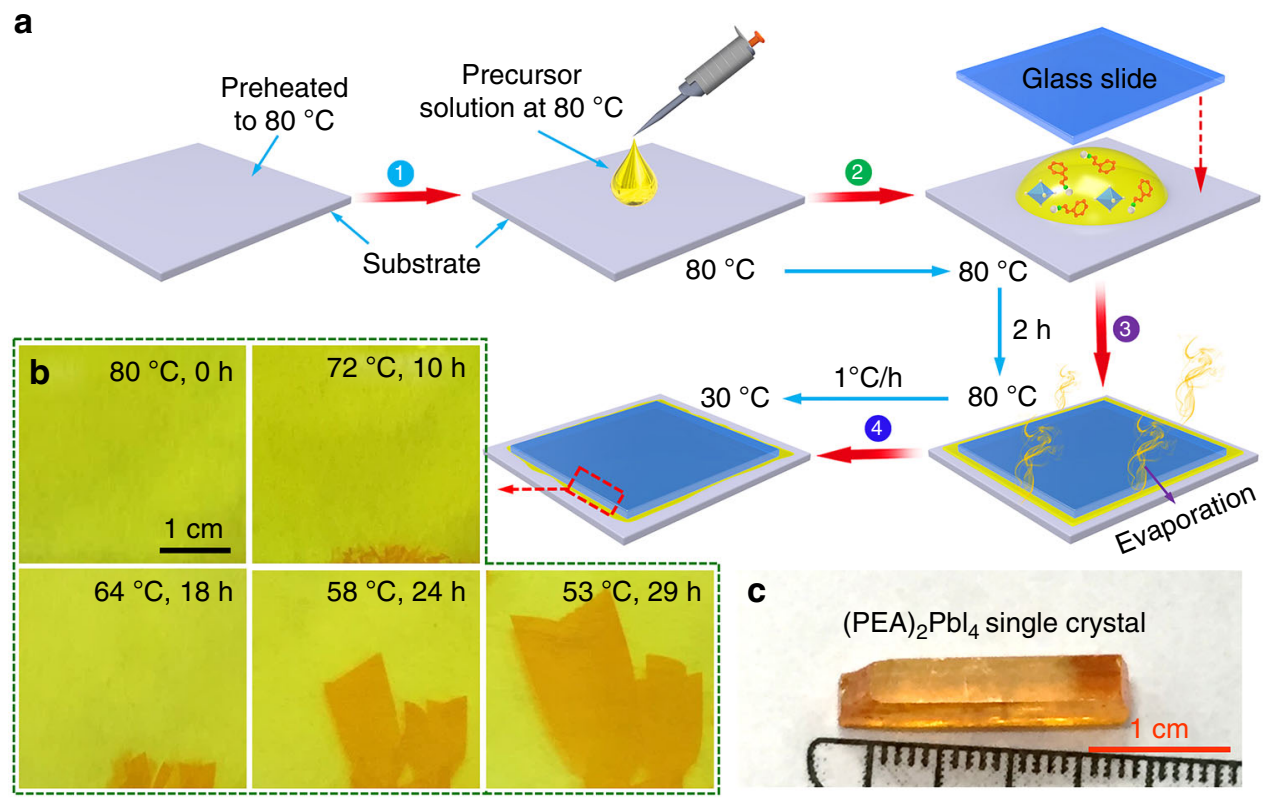

Fig. 2 IPC growth process of (PEA) ${ }_{2} \mathrm{Pbl}_{4} \mathrm{SCM}$. a Schematic illustration of the IPC procedure to grow $2 \mathrm{D}$ layered $(\mathrm{PEA})_{2} \mathrm{Pbl} \mathrm{S}_{4} \mathrm{SCM}$. $\mathbf{b} \mathrm{Photos}$ of a $(\mathrm{PEA})_{2} \mathrm{Pbl} \mathrm{I}_{4}$ $\mathrm{SCM}$ taken at different stages of the growth process. $\mathbf{c}$ Photo of a typical (PEA) ${ }_{2} \mathrm{Pbl}_{4}$ crystal.

about $3.45 \times 10^{-4}$, apparently lower comparing to its value $8.47 \times$ $10^{-4}$ at higher temperature beyond $80^{\circ} \mathrm{C}$, as shown in Fig. $1 \mathrm{~b}$. For the best quality at acceptable growth rate, we further regulated the temperature ramp rate to $1^{\circ} \mathrm{Ch}^{-1}$.

Figure 2a illustrates the IPC growth procedure. Briefly, $\mathrm{PbI}_{2}$ and $\mathrm{C}_{6} \mathrm{H}_{5} \mathrm{C}_{2} \mathrm{H}_{4} \mathrm{NH}_{3} \mathrm{I}$ (1:2 molar ratio) were dissolved in $\gamma$ butyrolactone (GBL) at $80^{\circ} \mathrm{C}$ under active mixing for $24 \mathrm{~h}$ to generate the $(\mathrm{PEA})_{2} \mathrm{PbI}_{4}$ precursor solution $(2.12 \mathrm{M})$. The solution was then filtered prior to crystal growth. For the growth of the $(\mathrm{PEA})_{2} \mathrm{PbI}_{4} \mathrm{SCM}$, a drop of the prepared precursor solution was pipetted onto a glass slide substrate (or flexible plastic substrate, polyethylene terephthalate (PET) substrate) preheated to $80^{\circ} \mathrm{C}$ as shown in step 1 . Then, a second glass slide with smaller lateral dimensions was placed onto the precursor solution drop. The solution was squeezed to spread evenly between two slides (step 2). It should be noted that part of the precursor solution was squeezed out to the edge of the top slide. Step 3 is to maintain the temperature at $80^{\circ} \mathrm{C}$ in an enclosed oven. In such case, the evaporation of the precursor solution along the edge of the top slide was well controlled at a consistent rate. In about $2 \mathrm{~h}$, nucleation and crystallization occurred at the edge of the top slide, as evidenced by some shinny crystallites. Further gradient decrease of the temperature from 80 to $30^{\circ} \mathrm{C}$ at a rate of $1{ }^{\circ} \mathrm{Ch}^{-1}$ led to the growth of the (PEA) $)_{2} \mathrm{PbI}_{4} \mathrm{SCM}$ between slides (step 4). In order to avoid crystallite growth in solution, the precursor was prepared at $80^{\circ} \mathrm{C}$ with concentration controlled at $2.12 \mathrm{M}(\mathrm{PEA})_{2} \mathrm{PbI}_{4}$ in $\mathrm{GBA}$ to warrant an unsaturated solution free of particulates that may serve as nucleation seeds. Everything used in the process, including glass slides and pipet, were preheated to $80^{\circ} \mathrm{C}$ to avoid local temperature change and associated crystallization during the entire operation of steps 1-3. At this temperature, the solution $(2.12 \mathrm{M})$ is unsaturated, therefore there is no possibility of crystallite formation anywhere. As the solvent around edges of the second glass slide was evaporated, the local solution concentration was slowly increased. When it surpasses the solubility curve, small crystallites start to form and grow larger. In step 4 , temperature of the set-up was gradually lowered. When it was dropped to below $75^{\circ} \mathrm{C}$, the solution became oversaturated, leading to crystal growth surrounding the nucleation seeds. As the process continues, the crystals grow into the slit until they filled the entire space. It is of vital importance for the edges of the 
second plate to provide nucleation sites to direct the crystals to grow inwards into the slit, rather than to form nanocrystalline powder from the solution. Figure $2 \mathrm{~b}$ shows five photographs of the $(\mathrm{PEA})_{2} \mathrm{PbI}_{4} \mathrm{SCMs}$ completed at different stages of the growth process. It shows that, without any seed crystal in the slit, there was no crystal formed when the temperature was kept at $80^{\circ} \mathrm{C}$. This is expected for, at the $80^{\circ} \mathrm{C}$, the solution is unsaturated. As the temperature was dropped to $72{ }^{\circ} \mathrm{C}$, small crystallites were formed along the edge of the glass slide. When the temperature was dropped to $64^{\circ} \mathrm{C}$, the small crystallite grew larger and eventually forming $5 \times 3 \mathrm{~mm}^{2} \mathrm{SCM}$ in the slit. When the temperature was further lowered to $53{ }^{\circ} \mathrm{C}$, the SCM grew larger to a $26 \times 15 \mathrm{~mm}^{2} \mathrm{SCM}$. Apparently, the perovskite crystallites are formed from the edge of the second slide, they then grow larger into the slit until the space is filled. However, when the identical procedure was carried out in a closed petri dish without using any slide from 80 to $30^{\circ} \mathrm{C}$, there formed a few well-shaped single crystals with habitant rectangular parallelepiped, as shown in Fig. 2c.

Thickness control and flexibility. Figure $3 a, b$ and Supplementary Fig. 1a, b present three-dimensional (3D) atomic force microscopy (AFM) images, with the height profiles clearly revealing successful fabrication of $(\mathrm{PEA})_{2} \mathrm{PbI}_{4} \mathrm{SCM}$ in thickness of 1.56 and $1.21 \mu \mathrm{m}$, respectively. It is found that the thickness of the (PEA) $)_{2} \mathrm{PbI}_{4}$ SCMs can be controlled by adjusting the cooling rate. The thickness distribution of the (PEA) $)_{2} \mathrm{PbI}_{4} \mathrm{SCMs}$ obtained with various cooling rates are as shown in Supplementary Fig. 2. Figure $3 \mathrm{c}$ provides cross-sectional scanning electron microscopic (SEM) images of a few typical (PEA) ${ }_{2} \mathrm{PbI}_{4}$ SCMs prepared using the IPC method with thickness ranging from 0.6 to $50 \mu \mathrm{m}$, with detailed characterizations and analyses shown in Supplementary Fig. 3. Supplementary Fig. 3a, b presents photos and SEM images of a representative (PEA) $)_{2} \mathrm{PbI}_{4} \mathrm{SCM}$, there is no cracking found in the area of $4.1 \times 1.8 \mathrm{~mm}^{2}$ inspected. Careful examination at higher resolution (Supplementary Fig. 3c) further confirms that the SCM is indeed single crystalline without observable grain boundaries. Supplementary Fig. 3d, e provides analysis using the energy-dispersive X-ray spectroscopy (EDS). It shows that the atomic ratio: $\mathrm{C}: \mathrm{Pb}: \mathrm{I}$ is approximately 18:1:4, consistent with the stoichiometry of $\left(\mathrm{C}_{6} \mathrm{H}_{5} \mathrm{C}_{2} \mathrm{H}_{4} \mathrm{NH}_{3}\right)_{2} \mathrm{PbI}_{4}$. In addition, EDS mapping analysis (Supplementary Fig. $3 \mathrm{f}-\mathrm{i}$ ) over area $0.56 \times 0.88$ $\mathrm{mm}^{2}$ shows very uniform atomic distribution. Moreover, there are some terraces observed along the edge of the $(\mathrm{PEA})_{2} \mathrm{PbI}_{4}$
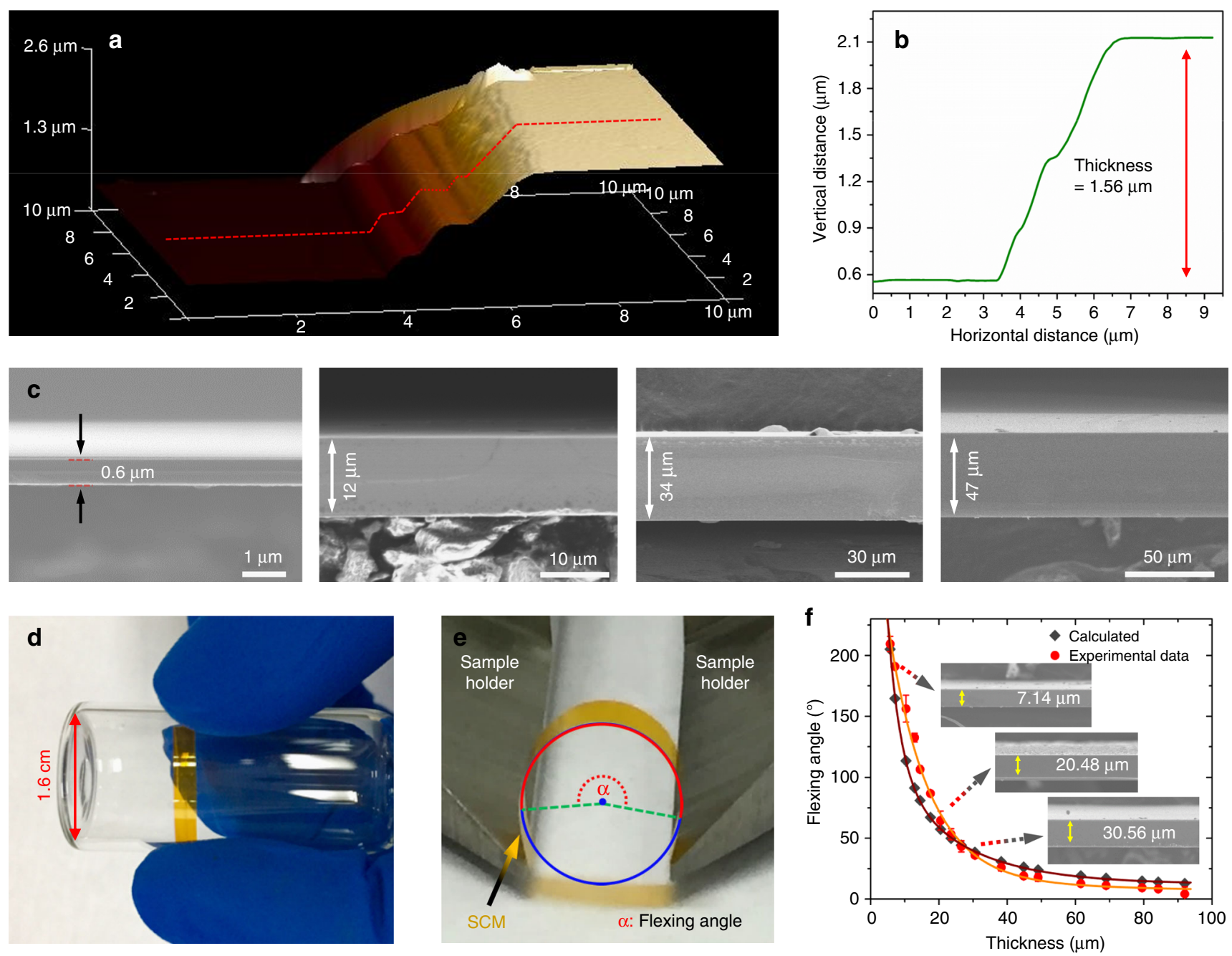

Fig. 3 Thickness control and flexibility of (PEA) ${ }_{2} \mathrm{Pbl}_{4} \mathrm{SCMs}$. a $3 \mathrm{D}$ AFM image of a (PEA) ${ }_{2} \mathrm{Pbl}_{4} \mathrm{SCM}$ and $\mathbf{b}$ height profile of the line scan. $\mathbf{c}$ Cross-sectional SEM images of the $(\mathrm{PEA})_{2} \mathrm{Pbl}_{4} \mathrm{SCMs}$ with different thicknesses $(0.6,12,34,47 \mu \mathrm{m})$. d Photo of a piece of $(\mathrm{PEA})_{2} \mathrm{Pbl}{ }_{4} \mathrm{SCM}, 3.5 \mu \mathrm{m}$ in thickness, wrapped around a small tube $\left(1.6 \mathrm{~cm}\right.$ in diameter) to show its flexibility. e A photo showing the flexing angle measurement for the $(\mathrm{PEA})_{2} \mathrm{Pbl}{ }_{4} \mathrm{SCM} . \mathbf{f} \mathrm{Correlation}$ of the $(\mathrm{PEA})_{2} \mathrm{Pbl}_{4} \mathrm{SCM}$ thickness and corresponding flexing angle, with the insets showing cross-sectional SEM images of the $(\mathrm{PEA})_{2} \mathrm{Pbl}{ }_{4} \mathrm{SCMs}$ with three thicknesses $(7.14,20.48,30.56 \mu \mathrm{m})$ 
a

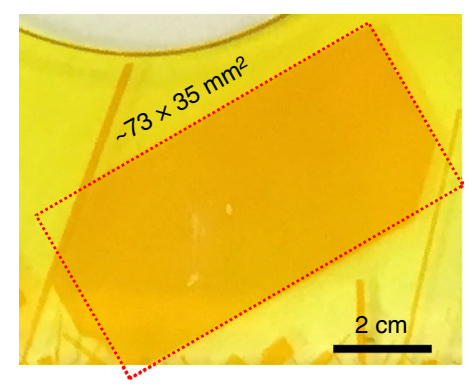

d

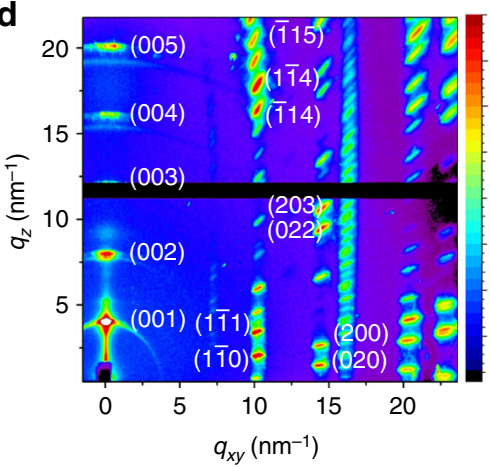

b

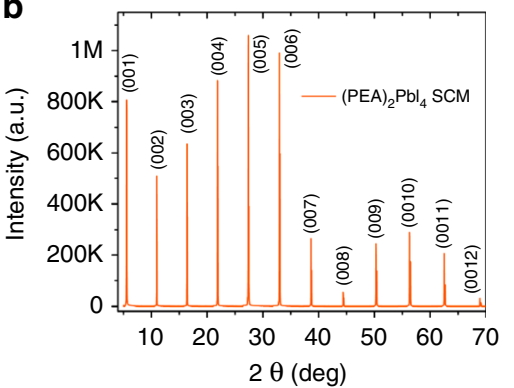

c

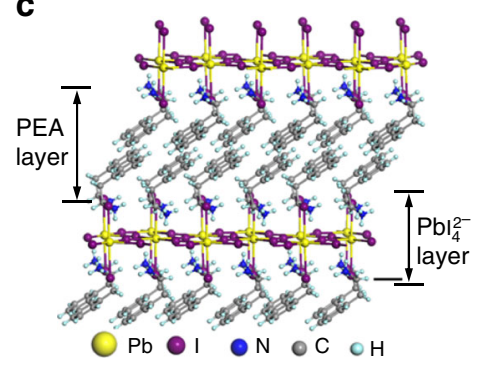

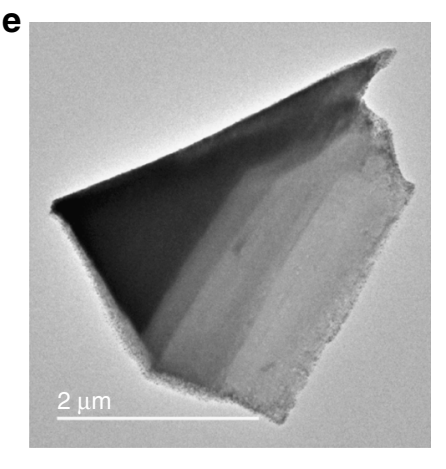

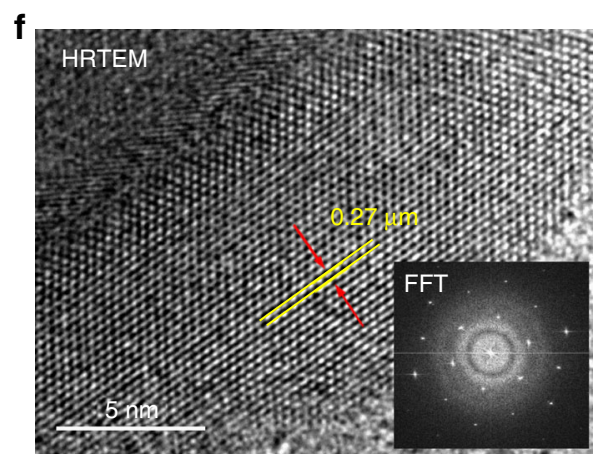

Fig. 4 Structural of $(P E A)_{2} \mathrm{Pbl}_{4} \mathrm{SCM}$. a Photo of the $(\mathrm{PEA})_{2} \mathrm{Pbl}_{4} \mathrm{SCM}$ sample $\left(73 \times 35 \mathrm{~mm}^{2}\right)$ used for XRD measurements. $\mathbf{b}$ XRD pattern of the $(\mathrm{PEA})_{2} \mathrm{Pbl} \mathrm{I}_{4}$ $\mathrm{SCM}$. $\mathbf{c}$ Layered crystal structure of the $(\mathrm{PEA})_{2} \mathrm{Pbl}_{4}$. d GIWAXS image of the $2 \mathrm{D}$ layered $(\mathrm{PEA})_{2} \mathrm{Pbl}_{4} \mathrm{SCM}$. e, $\mathbf{f}$ TEM image and HRTEM image of a $(\mathrm{PEA})_{2} \mathrm{Pbl}_{4} \mathrm{SCM}$, with the $\mathrm{d}$-spacing measured assigned to the (006) lattice plane

SCMs (Supplementary Fig. 4), demonstrating that the (PEA) ${ }_{2} \mathrm{PbI}_{4}$ SCM is indeed a layered (2D) material. It is worthwhile to note that the $2 \mathrm{D}$ layered perovskite $(\mathrm{PEA})_{2} \mathrm{PbI}_{4} \mathrm{SCMs}$ are flexible. As shown in Fig. 3d, the (PEA) ${ }_{2} \mathrm{PbI}_{4} \mathrm{SCM}$ with thickness of $3.5 \mu \mathrm{m}$ can be wrapped around on a small tube $(1.6 \mathrm{~cm}$ in diameter) without any deformation, demonstrating that the $(\mathrm{PEA})_{2} \mathrm{PbI}_{4}$ SCM is of very good flexibility. In fact, the (PEA) $)_{2} \mathrm{PbI}_{4} \mathrm{SCM}$ can be flexed in a wide range without observable fracture. Figure $3 e$ illustrates the measurement procedure for the flexing angle, the maximum bending angle tolerated before fracture, and Supplementary Fig. 5 shows a test for a 7.14- $\mu \mathrm{m}$-thick membrane in the range of flexing angle from $45^{\circ}$ to $195^{\circ}$. Figure $3 f$ shows the flexing angle as a function of the (PEA) ${ }_{2} \mathrm{PbI}_{4} \mathrm{SCM}$ thicknesses. It is found that, the thinner the membrane, the larger the flexing angle, the more flexible it is. Moreover, the curve showed a biexponential feature, consistent with the calculated result from elastic flexing deformation model for the layered materials (details described in Supplementary Fig. 6) ${ }^{65}$.

$$
\alpha=\frac{180^{\circ} L}{\pi d}
$$

where $L$ is the maximum stretching length, $\alpha$ is the flexing angle, and $d$ is half the thickness of the (PEA) ${ }_{2} \mathrm{PbI}_{4} \mathrm{SCM}$.

The above results demonstrate that the IPC is indeed a highly effective method to fabricate large-area flexible $(\mathrm{PEA})_{2} \mathrm{PbI}_{4} \mathrm{SCM}$. More importantly, flexible PET substrate has also been successfully tested to grow the (PEA) ${ }_{2} \mathrm{PbI}_{4} \mathrm{SCM}$, as the samples shown in Supplementary Fig. 7. Compared to the brittle 3D perovskite single crystals, e.g., $\mathrm{MAPbX}_{3}$ and $\mathrm{FAPbI}_{3}$ as we reported earlier ${ }^{1-}$ 3,30 , the $2 \mathrm{D}$ flexible layered (PEA) ${ }_{2} \mathrm{PbI}_{4} \mathrm{SCM}$ is of obvious advantages in flexible electronic devices, including flexible displays, wearable electronics, portable devices, ultrathin transistors, and special sensors.

Structural characterization. X-ray diffraction (XRD), grazingincidence wide-angle X-ray scattering (GIWAXS), and transmission electron microscopy (TEM) have been used to characterize the $(\mathrm{PEA})_{2} \mathrm{PbI}_{4} \mathrm{SCM}$ samples. Figure 4a shows a photo of a typical $(\mathrm{PEA})_{2} \mathrm{PbI}_{4} \mathrm{SCM}\left(73 \times 35 \mathrm{~mm}^{2}\right)$ on glass substrate used for the XRD measurement. The XRD in Fig. $4 \mathrm{~b}$ shows a series of sharp, intense, and well-defined diffraction peaks repeating periodically, signature of the $(00 h)(h=1,2,3 \ldots)$ planes in layered $(\mathrm{PEA})_{2} \mathrm{PbI}_{4}$ crystalline structure ${ }^{54,55}$ as shown in Fig. 4c. As it was previously observed, the $2 \mathrm{D}$ plane of the $(\mathrm{PEA})_{2} \mathrm{PbI}_{4} \mathrm{SCM}$ are preferentially parallel to the substrate ${ }^{45,55}$. Supplementary Fig. 8 shows the rocking curve corresponding to the (005) plane with the full-width at half maximum (FWHM) only $0.1055^{\circ}$, demonstrating respectable crystalline quality. To gain more insights into the orientation, GIWAXS were performed on both the (PEA) ${ }_{2} \mathrm{PbI}_{4} \mathrm{SCM}$ and a sample of corresponding MCTF. The GIWAXS image and the intensity versus $q$ for the scattering features of the (PEA) ${ }_{2} \mathrm{PbI}_{4} \mathrm{SCM}$ are shown in Fig. $4 \mathrm{~d}$ and Supplementary Fig. 9, respectively. We observed sharp, discrete Bragg spots at $q$ values of $10.14,14.40,16.16,20.13$, and $22.66 \mathrm{~nm}^{-1}$, corresponding to the $(00 h)(h=1,2,3 \ldots)$ planes in layered $(\mathrm{PEA})_{2} \mathrm{PbI}_{4}$ crystalline structure. This indicates perfect ordering and closed packing between each crystalline slab. Meanwhile, the synchrotron diffraction data indicate that the major perovskite growth is confined within the $(00 h)$ plane that is perpendicular to the $q_{z}$ direction ${ }^{66}$. In contrast, strong diffraction rings at $q=18.8 \mathrm{~nm}^{-1}$ and $q=23.8 \mathrm{~nm}^{-1}$ are observed for the microcrystalline counterpart (Supplementary Fig. 10), indicating considerable randomness in the orientation of the crystal grains due to the discontinued/misaligned stacking. The (PEA) ${ }_{2} \mathrm{PbI}_{4}$ SCM was further studied using high-resolution TEM analysis (HRTEM). Figure 4e shows the TEM image and Fig. 4f shows the crystal lattice image of the $(\mathrm{PEA})_{2} \mathrm{PbI}_{4} \mathrm{SCM}$ with a lattice spacing of $0.27 \mathrm{~nm}$, corresponding to the perovskite (006) plane, consistent with the XRD result.

Optical and transport properties. Optical properties of the $(\mathrm{PEA})_{2} \mathrm{PbI}_{4} \mathrm{SCM}$ were thoroughly studied, with the absorption 
a
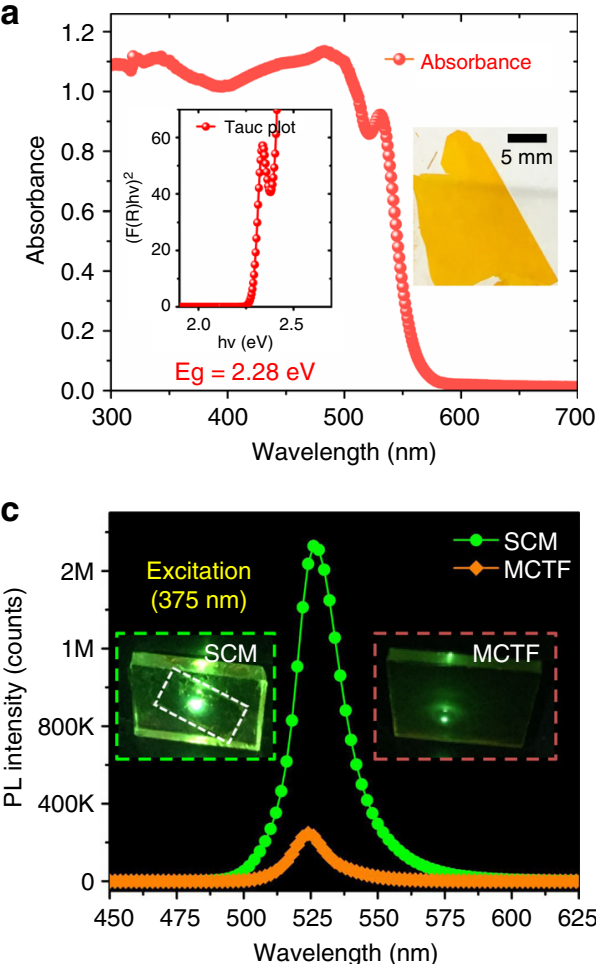

f

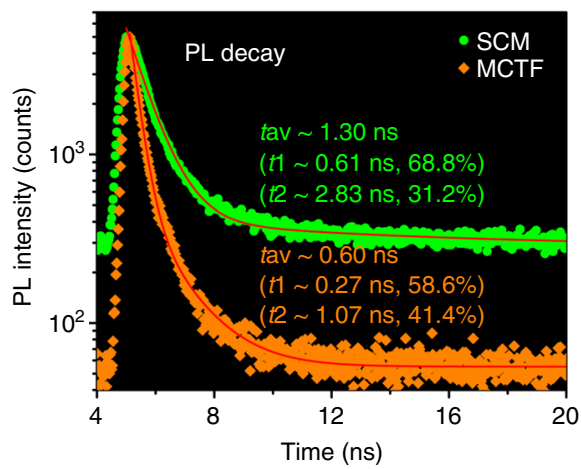

b
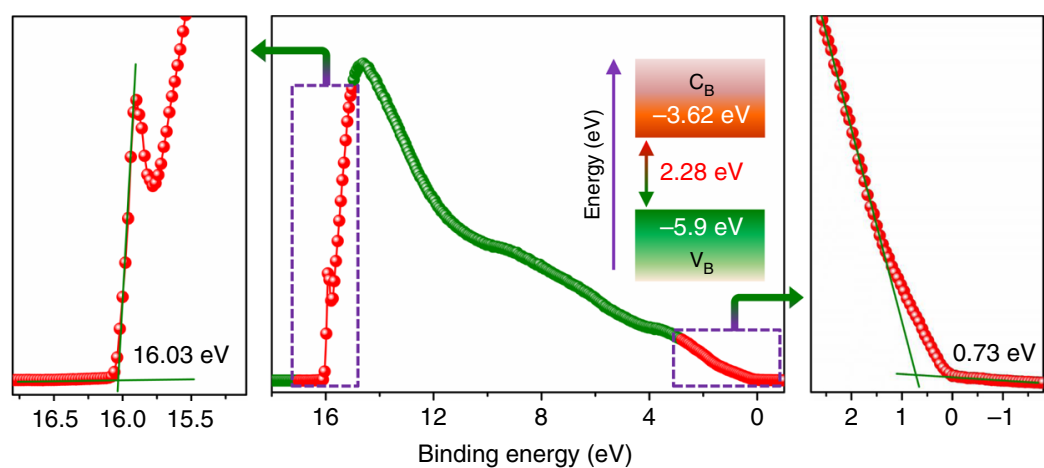

d
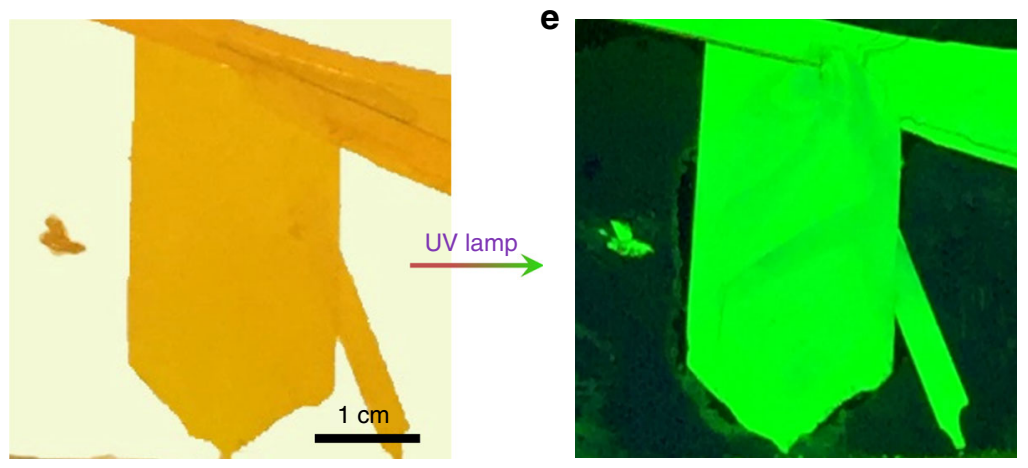

g

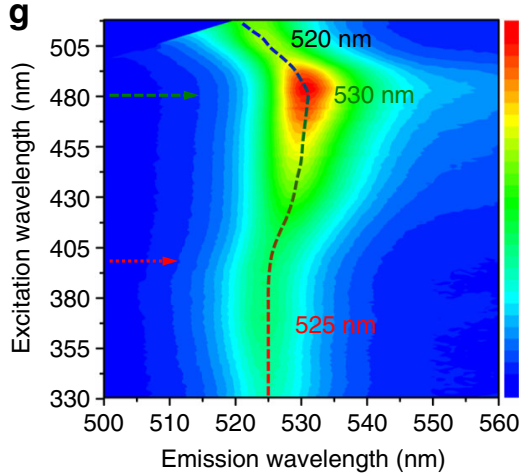

Fig. 5 Optical properties of (PEA) $)_{2} \mathrm{Pbl}_{4} \mathrm{SCM}$. a The absorbance spectrum and corresponding Tauc plot of the (PEA) ${ }_{2} \mathrm{Pbl}_{4} \mathrm{SCM}$ showing a band gap 2.27 $\mathrm{eV}$. The inset shows the photograph of the (PEA) ${ }_{2} \mathrm{Pbl}_{4} \mathrm{SCM}$ used for absorbance measurement. $\mathbf{b}$ Ultraviolet photoemission spectroscopy (UPS) of the $(\mathrm{PEA})_{2} \mathrm{Pbl}_{4} \mathrm{SCM}$. Insets: energy band diagram for the (PEA) ${ }_{2} \mathrm{Pbl}_{4} \mathrm{SCM}$. c Photoluminescence spectrum of the (PEA) ${ }_{2} \mathrm{Pbl}_{4} \mathrm{SCM}$ and MCTF excited at 375 $\mathrm{nm}$. Inset: the photo of the (PEA) ${ }_{2} \mathrm{Pbl}_{4} \mathrm{SCM}$ and MCTF excited at $375 \mathrm{~nm}$. d, e Photographs of the $(\mathrm{PEA})_{2} \mathrm{Pbl}_{4} \mathrm{SCM}$ under weak room light and strong UV lamp. f Time-resolved PL of the (PEA) ${ }_{2} \mathrm{Pbl}_{4} \mathrm{SCM}$ and MCTF at $525 \mathrm{~nm}$. The excitation laser beam wavelength is $375 \mathrm{~nm}$. Inset: Photograph of the green photoluminescence of a (PEA) ${ }_{2} \mathrm{Pbl}_{4} \mathrm{SCM}$ (left) and MCTF (right) excited by a $375 \mathrm{~nm}$ laser beam. $\mathbf{g} 3 \mathrm{D}$ excitation-emission plot for the (PEA) ${ }_{2} \mathrm{Pbl} \mathrm{S}_{4} \mathrm{SCM}$. Emission intensity rises with the color changing from blue to green and red. $\mathbf{h}$ Evolution of the photoluminescence spectrum shown using pseudocolor plot, indicating consistent emission peak wavelength and intensity across the large area

spectrum showing a sharp absorption edge at $550 \mathrm{~nm}$, corresponding to the bandgap of $2.28 \mathrm{eV}$ (Fig. 5a). This phenomenon is consistent with the absorption curve reported independently by other group on bulk crystals ${ }^{54}$. The optical band gaps estimated from the corresponding Tauc plots show values of 2.28 and 2.35 $\mathrm{eV}$ for the (PEA) ${ }_{2} \mathrm{PbI}_{4} \mathrm{SCM}$ and MCTF (Supplementary Fig. 11), respectively, in good agreement with previous report ${ }^{53,54}$. From ultraviolet photoelectron spectroscopy (UPS) results, we estimated the valence band edge position of $(\mathrm{PEA})_{2} \mathrm{PbI}_{4} \mathrm{SCM}$ to be $-5.90 \mathrm{eV}$ and for MCTF at $-5.44 \mathrm{eV}$, relative to the vacuum level (Fig. 5b and Supplementary Fig. 12). The (PEA) ${ }_{2} \mathrm{PbI}_{4} \mathrm{SCM}$ and MCTF samples were further characterized by photoluminescence (PL) spectra with a $375 \mathrm{~nm}$ laser excitation, as shown in Fig. 5c. The sharp and narrow peak at $525 \mathrm{~nm}(\mathrm{FWHM}=15.1 \mathrm{~nm})$ demonstrates the high color purity (narrow emission bandwidth) of the ( $\mathrm{PEA})_{2} \mathrm{PbI}_{4} \mathrm{SCM}$, an attractive feature for light-emitting applications. The PL peak centered at $521 \mathrm{~nm}$ for the MCTF $(\mathrm{PEA})_{2} \mathrm{PbI}_{4}$ is slightly blue-shifted compared to that in the (PEA) ${ }_{2} \mathrm{PbI}_{4} \mathrm{SCM}$ located at $525 \mathrm{~nm}$, indicating that the latter is indeed the SCM with lower defect density ${ }^{67}$. In addition, the PL intensity of the $(\mathrm{PEA})_{2} \mathrm{PbI}_{4} \mathrm{SCM}$ is much higher than that of the $(\mathrm{PEA})_{2} \mathrm{PbI}_{4} \mathrm{MCTF}$ under same test condition, as shown in the inset photograph. Figure $5 \mathrm{~d}$, e shows photos of the $(\mathrm{PEA})_{2} \mathrm{PbI}_{4}$ SCM taken under weak room light and ultraviolet (UV) lamp, respectively. It shows that, under the weak white light, the membrane appears to be yellowish in color and very uniform across the surface area. When it is exposed to strong UV irradiation, it becomes bright green with very uniform appearance. Apparently, the UV lamp has effectively excited the PL peaked at $525 \mathrm{~nm}$. The PL lifetimes of the $(\mathrm{PEA})_{2} \mathrm{PbI}_{4} \mathrm{SCM}$ and MCTF 
were measured using time-resolved PL. As shown in Fig. 5f, the decay curves show a biexponential feature with average lifetime of 1.3 and $0.6 \mathrm{~ns}$, respectively. More interestingly, we found that the $(\mathrm{PEA})_{2} \mathrm{PbI}_{4} \quad \mathrm{SCM}$ shows characteristic excitation-dependent fluorescence behavior, with the observed emission peaks shifting from 525 to $530 \mathrm{~nm}$ and to $520 \mathrm{~nm}$ with excitation wavelengths as shown in Fig. 5g. Specifically, when the excitation wavelength is $<400 \mathrm{~nm}$, the emission peak position is at $525 \mathrm{~nm}$. When the excitation wavelength is changed from 400 to $480 \mathrm{~nm}$, the emission peak shifts from 525 to $530 \mathrm{~nm}$. Further increasing the excitation wavelength, the emission peak is shifted from 530 to $520 \mathrm{~nm}$. This characteristic feature can also be observed on the MCTFs (Supplementary Fig. 13).

The PL is also used to study uniformity of the (PEA) $)_{2} \mathrm{PbI}_{4} \mathrm{SCM}$ sample. Surprisingly, the PL emission peak from 44 different points taken across the SCM is sharply centered at $525 \mathrm{~nm}$, with FWHM distributed within $14.8 \pm 0.14 \mathrm{~nm}$. More surprisingly, their peak intensity is maintained essentially the same at $3.87 \pm$ $0.02 \times 10^{4}$ counts (Fig. 5h and Supplementary Table 1). The standard deviation for these 44 tests is as low as $0.53 \%$ of their average intensity and only $0.95 \%$ for the FWHM, demonstrating good uniformity over large area for the high quality $(\mathrm{PEA})_{2} \mathrm{PbI}_{4}$ SCM. The automated PL intensity and lifetime mapping performed over surface area of $1 \mathrm{~cm}^{2}$ also exhibits far superior uniformity comparing to the corresponding MCTF (PEA) ${ }_{2} \mathrm{PbI}_{4}$ sample (Supplementary Fig. 14). The excellent optical uniformity makes it a promising candidate for large-area optoelectronic applications.

Trap-state density is another key figure-of-merit for optoelectronic and photovoltaic applications. Both electron-only and hole-only devices were therefore designed and fabricated for the measurement using the space-charge-limited current (SCLC) method $^{3}$. The dielectric constants $(\varepsilon)$ was determined to be 5.8 \pm 0.1 from the capacitance-frequency measurement in the range of $100 \mathrm{kHz}$ to $30 \mathrm{MHz}$ by impedance analyzer (Supplementary Fig. 15). Supplementary Fig. 16 presents the dark current-voltage $(I-V)$ curves for the single-carrier devices using the (PEA) $)_{2} \mathrm{PbI}_{4}$ SCM. Based on 8 measurements, the hole-trap density $\left(n_{\text {trap }}\right)$ was calculated as $(8.18 \pm 2.67) \times 10^{10} \mathrm{~cm}^{-3}$ (Supplementary Table 2), and the electron-trap density was calculated as $(1.66 \pm 0.88) \times 10^{11} \mathrm{~cm}^{-3} \quad$ (Supplementary Table 3). With low defect density and uniformity, the (PEA) ${ }_{2} \mathrm{PbI}_{4} \mathrm{SCM}$ should be ideal for optoelectronic applications. For real-world usage, stability becomes a critical factor for consideration. The thermal stability of the (PEA) $)_{2} \mathrm{PbI}_{4} \mathrm{SCM}$ was evaluated using thermogravimetric analysis (TGA), as shown in Supplementary Fig. 17. It shows that the $(\mathrm{PEA})_{2} \mathrm{PbI}_{4}$ SCM does not exhibit any observable degradation until $230^{\circ} \mathrm{C}$. We also tested its stability in high humidity environment by subjecting it to approximately $65 \%$ relative humidity at $25^{\circ} \mathrm{C}$ for 32 days. For the stability measurement, XRD was collected on a daily basis during the test period. As shown in Supplementary Fig. 18, there is no detectable decomposition in the $\mathrm{XRD}$ patterns after the long-term exposure, which suggests that the (PEA) ${ }_{2} \mathrm{PbI}_{4} \mathrm{SCM}$ is highly stable in humid condition. As its MCTF counterpart decomposes after $24 \mathrm{~h}$ in the same test, it is believed that the better stability of SCM is attributed to essentially eliminated solvent residues, grain boundaries, inclusions, and voids within the crystal. Supplementary Fig. 19 shows water contact angle tests to compare SCM with MCTF. While the contact angle for the reference MCTF sample measured is only $76^{\circ}$, it is increased to as much as $94^{\circ}$ for the (PEA) ${ }_{2} \mathrm{PbI}_{4} \mathrm{SCM}$ sample, demonstrating that the (PEA) ${ }_{2} \mathrm{PbI}_{4} \mathrm{SCM}$ is significantly poorer in wettability or better in water/moisture resistance.
Device performance of flexible photosensor. With all above superior properties including low defect density, good uniformity, long-term stability and adequate flexibility, we are inspired to expand its application into flexible photosensors, as designed with the architecture schematically illustrated in Supplementary Fig. 20 and the working mechanism is described in Fig. 6a, b. Please note that the devices in this manuscript are designed using the metal-semiconductor-metal structure with interdigitated electrodes. As the photogenerated electrons may be trapped by shallow defects, holes may traverse between the electrodes for multiple times before recombination, in other words, holes drift along the electric field until they reach the electrode while electrons remain trapped in "doping centers." To maintain charge neutrality, mobile holes are continuously recirculated between electrodes (majority carrier recirculation) ${ }^{68,69}$. Consequently, for each electron-hole pair created, holes may bounce between two electrodes repeatedly for multiple times, resulting in recirculation for abnormally high photoconductive gain.

The effectively illuminated device area is measured to be $4.54 \times$ $10^{-2} \mathrm{~mm}^{2}$. In order to study its response as a function of bias and light intensity, the $I-V$ curves were measured in dark and under $460 \mathrm{~nm}$ light illumination with intensity ranging from $8 \times 10^{-5}$ to $310 \mathrm{~mW} \mathrm{~cm}^{-2}$ (Fig. 6c). The dark current is measured as low as $1.62 \times 10^{-3} \mathrm{nA}$ or $3.57 \times 10^{-6} \mathrm{~mA} \mathrm{~cm}^{-2}$ at $2 \mathrm{~V}$ bias; the light current of the same device increases to $1068 \mathrm{nA}$ or $2.35 \mathrm{~mA} \mathrm{~cm}^{-2}$ under illumination intensity of $10 \mathrm{~mW} \mathrm{~cm}^{-2}$, exceeding 5 orders of magnitude enhancement comparing to its dark current. It should be noted that, the dark current of the present $(\mathrm{PEA})_{2} \mathrm{PbI}_{4}$ SCM device is strikingly lower than the control device made of 3D perovskite single-crystal wafer (Supplementary Table 4). In general, the dark current decreases as the material quality increases. In other words, devices with fewer defects are expected to show lower dark current. To compare the optoelectronic performance between the (PEA) $)_{2} \mathrm{PbI}_{4} \mathrm{SCM}$ and MCTF, the $I-V$ curves of their corresponding devices were measured under illumination, as shown in Supplementary Fig. 21. Under the same illumination condition, photocurrent of the (PEA) ${ }_{2} \mathrm{PbI}_{4} \mathrm{MCTF}$ device measured only $0.12 \mathrm{nA}$ or $2.64 \times 10^{-4} \mathrm{~mA} \mathrm{~cm}^{-2}$, about 8900 times smaller.

The key sensor parameters such as $R$, EQE, and $D^{*}$ are calculated and provided in Supplementary Information. Figure 6d shows the photoresponse as a function of the incident light intensity. Both the photocurrent density and $R$ show good linear correlation with high correlation coefficients (0.999). It can be seen that the photocurrent of the SCM devices show a linear response from $8 \times 10^{-5}$ to $310 \mathrm{~mW} \mathrm{~cm}^{-2}$, with an linear dynamic range (LDR) of $124 \mathrm{~dB}$. Figure $6 \mathrm{f}$ shows the EQE for the flexible photosensor based on the (PEA) ${ }_{2} \mathrm{PbI}_{4} \mathrm{SCM}$ within the illumination intensity ranging from $8 \times 10^{-5}$ to $310 \mathrm{~mW} \mathrm{~cm}^{-2}$ at wavelength of $460 \mathrm{~nm}$ under a $4 \mathrm{~V}$ bias. To obtain the detectivity $\left(D^{*}\right)$, we first directly recorded the noise current by a dynamic signal analyzer, a method that has been well established by Tang et al. and Huang et al. ${ }^{69,70}$. As shown in Fig. 6e, the measured average noise current of the (PEA) ${ }_{2} \mathrm{PbI}_{4} \mathrm{SCM}$ photosensor is approximately $1.29 \times 10^{-15} \mathrm{~A} \mathrm{~Hz}^{-1 / 2}$. It can be seen that the noise current is independent of the frequency, indicating that the noise of the present devices is not dominated by the $1 / f$ noise due to the minimized trap density and the absence of grain boundaries in the $(\mathrm{PEA})_{2} \mathrm{PbI}_{4} \mathrm{SCMs}^{69,70}$. The two main noise sources are the shot noise $\left(i_{\mathrm{n}, \mathrm{s}}\right)$ and the thermal noise $\left(i_{\mathrm{n}, \mathrm{t}}\right)$, respectively. The shot noise $\left(i_{\mathrm{n}, \mathrm{s}}\right)$ can be calculated from the dark current using the following equation:

$$
i_{\mathrm{n}, \mathrm{s}}=\sqrt{2 e i_{\mathrm{d}} B}
$$


a

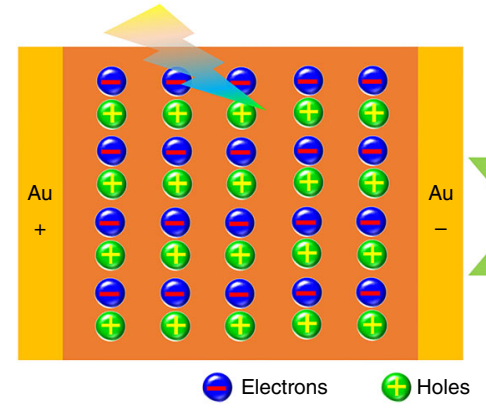

d

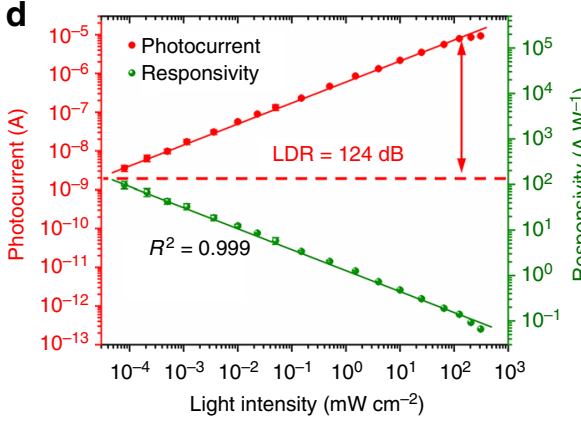

g

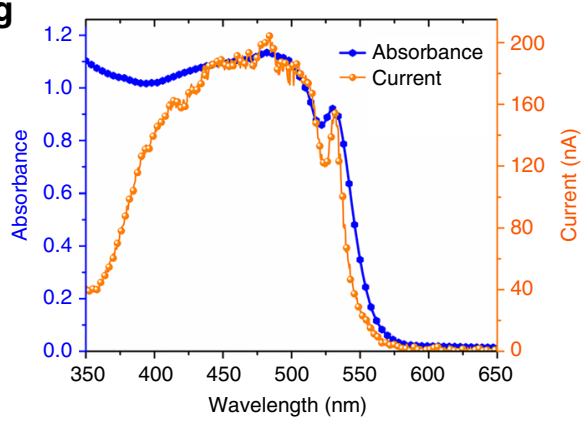

b
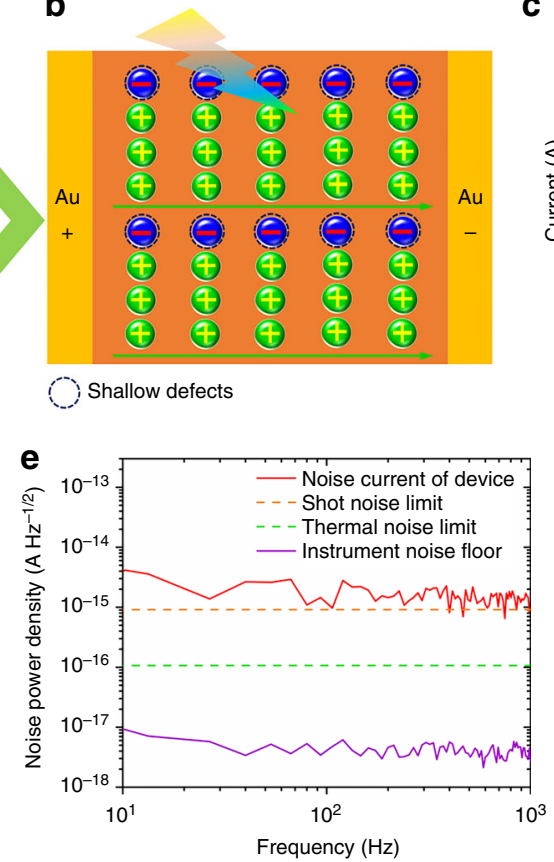

h

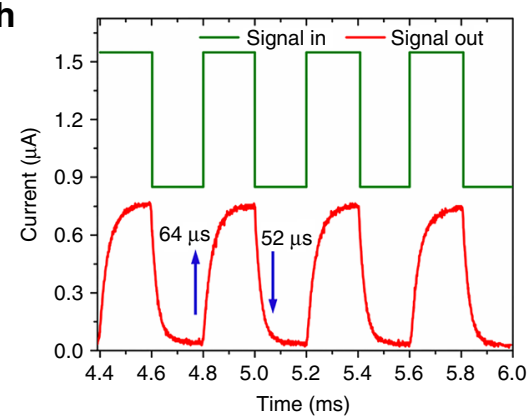

C

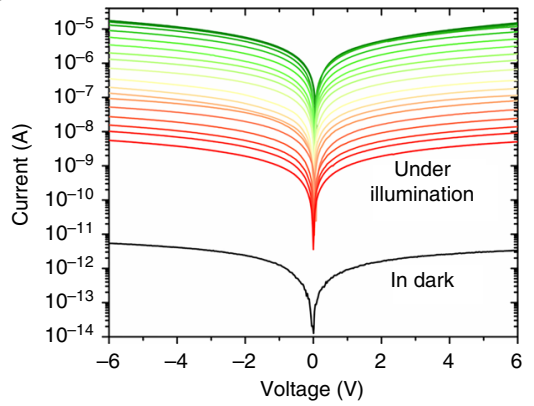

f

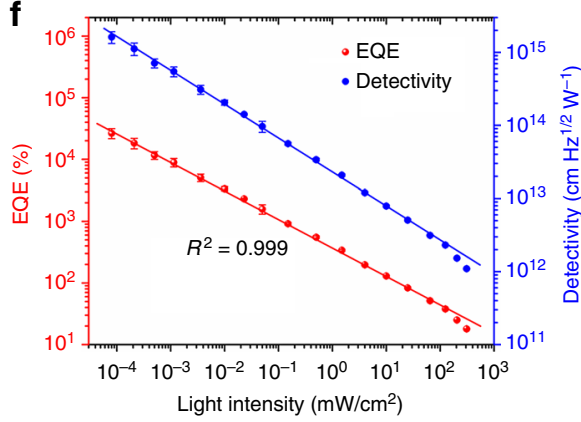

i

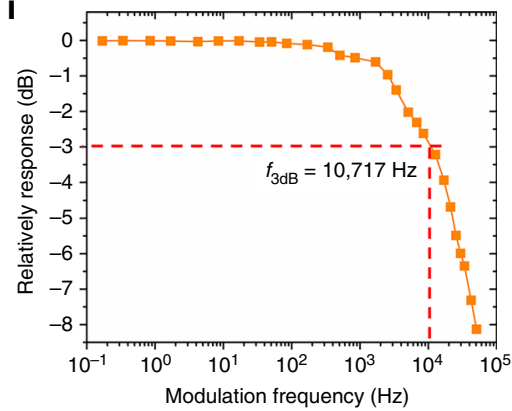

Fig. 6 Performance of flexible (PEA) ${ }_{2} \mathrm{Pbl}_{4} \mathrm{SCM}$ photosensor. $\mathbf{a}, \mathbf{b}$ Schematic illustrations of the photoelectric process and photoconductivity gain in the present $\mathrm{Au} /(\mathrm{PEA})_{2} \mathrm{Pbl}_{4} \mathrm{SCM} / \mathrm{Au}$ device under light illumination. $\mathbf{c}$ The current-voltage $(I-V)$ curves of the (PEA $)_{2} \mathrm{Pbl}_{4} \mathrm{SCM}$ device measured in dark and under $460 \mathrm{~nm}$ wavelength illumination with various light intensities. d Photocurrent and responsivity for the (PEA) ${ }_{2} \mathrm{Pbl}_{4} \mathrm{SCM}$ photosensors within the incident light power density ranging from $8 \times 10^{-5}-310 \mathrm{~mW} \mathrm{~cm}^{-2}$ at wavelength $460 \mathrm{~nm}$ under a fixed $4 \mathrm{~V}$ bias. e Measured dark current noise at various frequencies of the $(\mathrm{PEA})_{2} \mathrm{Pbl}_{4} \mathrm{SCM}$ photosensor with a $4 \mathrm{~V}$ bias. The measured instrument noise floor, calculated shot noise, and thermal noise limit are also included for reference. $\mathbf{f} E Q E$ and $D^{\star}$ for the $(\mathrm{PEA})_{2} \mathrm{Pbl}_{4} \mathrm{SCM}$ photosensor within the incident light power density ranging from $8 \times 10^{-5}-310 \mathrm{~mW} \mathrm{~cm}^{-2}$ at wavelength $460 \mathrm{~nm}$ under a fixed $4 \mathrm{~V}$ bias. The points correspond to average values of measurements on $20(\mathrm{PEA})_{2} \mathrm{Pbl}_{4} \mathrm{SCM}$ photosensors, and the error bars represent the standard deviation. $\mathbf{g}$ Absorbance spectrum of the (PEA) ${ }_{2} \mathrm{Pbl}_{4} \mathrm{SCM}$ and photoresponse spectrum of the photosensor illuminated using monochromatic light with wavelength ranging from 350 to $650 \mathrm{~nm}$ at $4 \mathrm{~V}$ bias. $\mathbf{h}$ Temporal photocurrent response of the (PEA) ${ }_{2} \mathrm{Pbl}{ }_{4} \mathrm{SCM}$ photosensor. i Frequency response of the (PEA) ${ }_{2} \mathrm{Pbl}_{4} \mathrm{SCM}$ photosensor

where $i_{\mathrm{d}}$ is the dark current, $e$ the elementary charge, and $B$ the electrical bandwidth. Based on dark current of the device at $4 \mathrm{~V}$ bias, the shot noise is calculated to be $9.12 \times 10^{-16} \mathrm{~A} \mathrm{~Hz}^{-1 / 2}$. Besides the shot noise, the thermal noise $\left(i_{\mathrm{n}, \mathrm{t}}\right)$ is determined by the following equation:

$$
i_{\mathrm{n}, \mathrm{t}}=\sqrt{\frac{4 k_{\mathrm{B}} T B}{R}}
$$

where $k_{\mathrm{B}}$ is the Boltzmann constant, $T$ the temperature, and $R$ the resistance of the $(\mathrm{PEA})_{2} \mathrm{PbI}_{4} \mathrm{SCM}$ photosensor. Based on the dark current curve, the resistance at $4 \mathrm{~V}$ is obtained and so that the thermal noise is calculated to be $1.03 \times 10^{-16} \mathrm{~A} \mathrm{~Hz}^{-1 / 2}$. Undoubtedly, large resistivity of the photosensor resulted in low dark current, small shot noise, and low thermal noise. The total noise $\left(i_{\mathrm{n}, \mathrm{T}}\right)$ can be calculated according to the expression below:

$$
i_{\mathrm{n}, \mathrm{T}}=\sqrt{i_{\mathrm{n}, \mathrm{s}}^{2}+i_{\mathrm{n}, \mathrm{t}}^{2}}
$$

As a result, the calculated total noise limit $9.18 \times 10^{-16} \mathrm{~A}$ $\mathrm{Hz}^{-1 / 2}$ by only considering the shot noise and thermal noise is very close to the measured noise $1.29 \times 10^{-15} \mathrm{~A} \mathrm{~Hz}^{-1 / 2}$. Based on the measured dark current noise $\left(i_{\mathrm{n}}\right)$ and the responsivity $(R)$ of the photosensor, the noise equivalent power (NEP) can be calculated by the following equation:

$$
\mathrm{NEP}=\frac{i_{\mathrm{n}}}{R}
$$


Accordingly, the specific detectivity $\left(D^{\star}\right)$ of the photosensor is deduced by the following equation:

$$
D^{*}=\frac{\sqrt{A B}}{\mathrm{NEP}}=\frac{R \sqrt{A B}}{i_{\mathrm{n}}}
$$

where $A$ is the active area of the device and $B$ the electrical bandwidth. Finally, $D^{*}$ is calculated and shown in Fig. $6 \mathrm{f}$ as a function of the illumination intensity ranging from $8 \times 10^{-5}$ to $310 \mathrm{~mW} \mathrm{~cm}^{-2}$ at wavelength of $460 \mathrm{~nm}$ with a fixed $4 \mathrm{~V}$ bias. Because of more charge recombination occurred under higher illumination intensity, all values of $R, \mathrm{EQE}$, and $D^{*}$ decrease as the incident light intensity increases. Figure $6 \mathrm{~g}$ shows its spectral photocurrent response. As expected, the photosensor shows high response in the wavelength region of $350-550 \mathrm{~nm}$, consistent with its optical absorption. $R, \mathrm{EQE}$, and $D^{*}$ against various wavelength under a fixed $4 \mathrm{~V}$ bias are calculated and shown in Supplementary Fig. 22. Under the lowest measured incident light, power density achieves $8 \times 10^{-5} \mathrm{~mW} \mathrm{~cm}^{-2}$, and the highest $R, \mathrm{EQE}$, and $D^{*}$ are calculated to be $98.17 \mathrm{~A} \mathrm{~W}^{-1}, 2.65 \times 10^{4} \%$ and $1.62 \times 10^{15} \mathrm{~cm}$ $\mathrm{Hz}^{1 / 2} \mathrm{~W}^{-1}$ (Jones), respectively. Note that the extraordinarily high $D^{*}$ value of the present device (exceeding $10^{15} \mathrm{~cm} \mathrm{~Hz}^{1 / 2}$ $\mathrm{W}^{-1}$ ) is among the record high reported for the perovskite photosensors so far, and it is even higher than that of devices based on single-crystalline silicon ${ }^{56}, \mathrm{InGaAs}^{57}, \mathrm{GaAs}^{58}, \mathrm{CdTe}^{59}$, and $\mathrm{GaN}^{60}$, demonstrating much superior quality of the $2 \mathrm{D}$ layered $(\mathrm{PEA})_{2} \mathrm{PbI}_{4}$ single-crystalline perovskite membrane material.

Supplementary Fig. 23a presents the time-dependent on/off cycle test. Clearly, the device is very stable during the test process under multiple repeated on/off cycles with the bias at $0.5,1,2,3$, and $4 \mathrm{~V}$. The photocurrent response as a function of bias voltage of the photosensors is provided in Supplementary Fig. 23b. It is found that there is a good linear correlation with high correlation coefficients (approximately 1). Furthermore, we measured the response time of the $(\mathrm{PEA})_{2} \mathrm{PbI}_{4} \mathrm{SCM}$ photosensors. The rise time $\left(t_{\text {rise }}\right)$ is generally defined in literature as time needed for the photocurrent to rise from $10 \%$ peak value to $90 \%$ and inverse for the decay time $\left(t_{\text {decay }}\right)$. As shown in Fig. $6 \mathrm{~h}$, the photosensor shows the response speed with the photocurrent rise and fall times as 64 and $52 \mu$ s, respectively. Figure $6 \mathrm{i}$ depicts the plot of the frequency responses of the photosensor, showing a $-3 \mathrm{~dB}$ cutoff frequency up to $10.72 \mathrm{KHz}$. Undoubtedly, the fast photocurrent response of these photosensors can be attributed to very low defect density of the SCM. More detailed comparison is provided in Supplementary Table 5.

Apart from the stability and detectivity, the mechanical flexibility is also an important parameter for the photosensors. To assess the flexibility of the present $(\mathrm{PEA})_{2} \mathrm{PbI}_{4} \mathrm{SCM}$ photosensor, the optoelectronic performance of the device has been measured precisely at various bending angles under constant incident light intensity. The corresponding photocurrents are shown in Supplementary Fig. 24a-f. When compared with the original data given in Supplementary Fig. 24a, the responsivities decrease slightly, and the reduction is calculated to be approximately $8 \%$, even when the sensor is bent to $155^{\circ}$ of flexing angle (Supplementary Fig. 24f), thus demonstrating the superior flexibility of the photosensor.

\section{Discussion}

In summary, we have developed an effective process to grow high-quality flexible $2 \mathrm{D}$ layered (PEA) ${ }_{2} \mathrm{PbI}_{4} \mathrm{SCM}$. Under optimal temperature ramp rate, the size of these SCMs is $>73 \times 35 \mathrm{~mm}^{2}$, with thickness as thin as $0.6 \mu \mathrm{m}$. As far as we know, this is the first time to grow flexible perovskite SCM with thickness thinner than $10 \mu \mathrm{m}$ and area exceeding $2500 \mathrm{~mm}^{2}$. XRD, GIWAXS, and
TEM analyses confirm that the SCMs are of layered structure. In addition, the SCM displays very low defect density, long-term stability, and excellent flexibility. It is also found that the assynthesized (PEA) ${ }_{2} \mathrm{PbI}_{4} \mathrm{SCM}$ shows excitation-dependent fluorescence behavior. Finally, the flexible perovskite SCM with large surface area opens a way for its application in high-performance flexible planar photosensors. The successful growth and further utilization of the flexible $2 \mathrm{D}$ layered $(\mathrm{PEA})_{2} \mathrm{PbI}_{4} \mathrm{SCM}$ not only provide a new material system but also open up an avenue to applications in optoelectronics.

\section{Methods}

Materials. GBL (99\%) and Lead iodide $\left(\mathrm{PbI}_{2}, 99 \%\right)$ were purchased from Aladdin Reagent Ltd. Phenylethylammonium iodide (PEAI, 99\%) was purchased from Xi'an Polymer Light Technology Corp. All the chemicals were used as received without further purification.

Fabrication of the (PEA) ${ }_{2} \mathrm{Pbl}_{4}$ single-crystal membranes (SCMs). Induced peripheral crystallization procedure is schematically illustrated in Fig. 2a. Briefly, $\mathrm{PbI}_{2}$ and PEAI (1:2 molar ratio) were dissolved in $\mathrm{GBL}$ at $80^{\circ} \mathrm{C}$ under active mixing for $24 \mathrm{~h}$ to generate the (PEA) ${ }_{2} \mathrm{PbI}_{4}$ precursor solution $(2.12 \mathrm{M})$. The solution was then filtered prior to crystal growth. For the growth of the (PEA) ${ }_{2} \mathrm{PbI}_{4} \mathrm{SCM}$, a drop of the prepared precursor solution was pipetted onto a glass slide substrate (or flexible plastic substrate, PET substrate) preheated to $80^{\circ} \mathrm{C}$ as shown in step 1 . Then a second glass slide with smaller lateral dimensions was placed onto the precursor solution drop. The solution was squeezed to spread evenly between two glass slides (step 2). It should be noted that part of the precursor solution was squeezed out to the edge of the top slide. Step 3 is to maintain the temperature of the entire assembly at $80^{\circ} \mathrm{C}$ in an enclosed oven. In such case, the evaporation the precursor solution along the edge of the top slide was well controlled at a consistent rate. In about $2 \mathrm{~h}$, nucleation and crystallization occurred at the edge of the top slide, as evidenced by some shinny crystallites formed along the edges of the second slide. Further gradient decrease of the temperature from 80 to $30^{\circ} \mathrm{C}$ at a rate of $1{ }^{\circ} \mathrm{C} \mathrm{h}^{-1}$ led to the growth of the (PEA) ${ }_{2} \mathrm{PbI}_{4} \mathrm{SCM}$ between the slides (step 4).

Fabrication of the (PEA) $\mathbf{2}_{\mathbf{2}} \mathbf{P b l}_{\mathbf{4}} \mathbf{M C T F s}$. The glass substrate was cleaned by successive sonication with acetone, isopropanol, and ethanol for $30 \mathrm{~min}$ and then dried with $\mathrm{N}_{2}$ flow. The clean substrate was then treated with UV-Ozone for 15 min before solution casting. Precursor solution $(70 \mu \mathrm{L})$ was dropped on the fresh-prepared glass substrate followed by spin-coating at 5000 r.p.m. for $20 \mathrm{~s}$ without delay. The as-cast films were then annealed at $100{ }^{\circ} \mathrm{C}$ for $10 \mathrm{~min}$. The spincoating was accomplished under inert atmosphere inside a nitrogen-filled glove box.

Fabrication of devices for relative dielectric constant $(\varepsilon)$ measurements. Seven devices were fabricated by depositing Au electrodes (100-nm thickness) on two opposite surfaces of the (PEA) ${ }_{2} \mathrm{PbI}_{4}$ SCMs.

Fabrication of devices for SCLC measurements. The devices were fabricated by depositing the $\mathrm{Au}$ electrodes (approximately 100-nm thickness) with the architecture of $\mathrm{Au} /(\mathrm{PEA})_{2} \mathrm{PbI}_{4} \mathrm{SCM} / \mathrm{Au}$ for hole-only devices and $\mathrm{Au} / \mathrm{PCBM} /$ (PEA) ${ }_{2} \mathrm{PbI}_{4} \mathrm{SCM} / \mathrm{PCBM} / \mathrm{Au}$ for electron-only devices.

\section{Fabrication of the (PEA) ${ }_{2} \mathrm{Pbl}_{4}$ SCM planar photodetectors. Planar photo-} detectors were fabricated by depositing interdigital Au electrodes (200-nm thickness) via vacuum evaporation method on the (PEA) $)_{2} \mathrm{PbI}_{4} \mathrm{SCMs}$ and $(\mathrm{PEA})_{2} \mathrm{PbI}_{4}$ MCTFs. The bridging gap of electrode width is $20 \mu \mathrm{m}$, while the effective illuminated area of each device was about $4.54 \times 10^{-2} \mathrm{~mm}^{2}$.

Characterization. Powder XRD and high-resolution XRD on SC wafer: XRD patterns were collected using a Bruker D8 Advance X-ray diffractometer equipped with a Cu tube $(\lambda=1.5406 \AA)$ operated at $40 \mathrm{kV}$ and $20 \mathrm{~mA}$. High-resolution XRD measurement was taken using X'Pert MRD, with $\mathrm{Cu}$ Kal line $(\lambda=1.5406 \AA)$ with $V=40 \mathrm{KV}$ and $I=20 \mathrm{~mA}$.

Grazing-incidence wide angle X-ray scattering: GIWAXS measurements were performed at D line at the Cornell High Energy Synchrotron Source. The wavelength of the X-rays was $1.157 \AA$ with a bandwidth $\Delta \lambda / \lambda$ of $1.5 \%$. The scattering signal was collected by Pilatus $200 \mathrm{~K}$ detector, with a pixel size of $172 \times$ $172 \mu \mathrm{m}^{2}$ placed at $191 \mathrm{~mm}$ away from the sample position. The incident angle of the X-ray beam was at $0.30^{\circ}$ and the integration time was $1 \mathrm{~s}$.

Thermal analysis: TGA was performed on a TA SDT-Q600 V20.9 (Build 20). The sample was placed in an $\mathrm{Al}_{2} \mathrm{O}_{3}$ crucible and heated in an interval from room temperature to $800{ }^{\circ} \mathrm{C}$ at a ramp rate $5^{\circ} \mathrm{C} \mathrm{min}-1$ under flowing nitrogen gas with a flow rate $100 \mathrm{~mL} \mathrm{~min}^{-1}$. About $3 \mathrm{mg}$ of $(\mathrm{PEA})_{2} \mathrm{PbI}_{4} \mathrm{SCM}$ powder was used for the TGA measurements. 
UV-Vis-near infrared (NIR) absorbance spectra measurements: UV-Vis absorbance spectrum of (PEA) ${ }_{2} \mathrm{PbI}_{4} \mathrm{SCMs}$ and (PEA) ${ }_{2} \mathrm{PbI}_{4}$ MCTFs were measured using a Perkin-Elmer Lambda 950 UV-Vis-NIR spectrophotometer equipped with an integrating sphere attachment operating in the $300-800 \mathrm{~nm}$ region at room temperature.

UPS measurements: UPS was performed on a photoelectron spectrometer (ESCALAB 250Xi, Thermo Fisher Scientific) to study the working function of the $(\mathrm{PEA})_{2} \mathrm{PbI}_{4} \mathrm{SCMs}$ and $(\mathrm{PEA})_{2} \mathrm{PbI}_{4}$ MCTFs.

Steady-state and time-resolved PL measurements: Steady-state and timeresolved PL measurements of $(\mathrm{PEA})_{2} \mathrm{PbI}_{4} \mathrm{SCMs}$ and $(\mathrm{PEA})_{2} \mathrm{PbI}_{4}$ MCTFs were taken using a PicoQuant FT-300 and FT-100, with $375 \mathrm{~nm}$ excitation wavelength. All PL spectra were measured in air without encapsulation.

Relative dielectric constant measurements: Capacitance of the $(\mathrm{PEA})_{2} \mathrm{PbI}_{4}$ SCMs were determined using the impedance analyzer (Agilent 4294 A Precision LCR Meter) over a wide frequency range from $100 \mathrm{kHz}$ up to $30 \mathrm{MHz}$ (Figure S10a). The relative dielectric constant of the prepared samples was calculated using the capacitance.

SCLC measurements: The single carrier devices were fabricated and used to measure the trap-state density by using the SCLC method for the $(\mathrm{PEA})_{2} \mathrm{PbI}_{4}$ SCMs. The structure is $\mathrm{Au} /(\mathrm{PEA})_{2} \mathrm{PbI}_{4} \mathrm{SCM} / \mathrm{Au}$ for hole-only devices and $\mathrm{Au} /$ $\mathrm{PCBM} /(\mathrm{PEA})_{2} \mathrm{PbI}_{4} \mathrm{SCM} / \mathrm{PCBM} / \mathrm{Au}$ for electron-only devices. The dark $I-V$ curve was measured using the Keithley 4200 semiconductor characterization system and was used to calculate the trap-state density.

Photosensor performance measurements: All device performance characterizations were done in a dark box with optical and electrical shielding to minimize electromagnetic and ambient light disturbance. The photoresponse characteristics were measured using the Keithley 4200 semiconductor characterization system and a manual probe station under various bias voltages. To measure the response speed, a $462 \mathrm{~nm}$ semiconductor laser driven by a signal generator (Tektronix, AFG3252C) was used as the light source to generate pulsed laser beam, and the temporal response of the device was measured by using a LowNoise Current Preamplifier (Stanford Research System, SR570) with a Mixed Domain Oscilloscope (Tektronix, MDO3104). For wavelength-dependent photocurrent measurement, the spectrum was generated by modulating a xenon lamp equipped with a monochromator. Noise currents were measured by using a spectrum analyzer (Keysight $35670 \mathrm{~A})$. A resistor $(10 \mathrm{M} \Omega$ ) was connected in series with the device and the frequency analyzer was connected in parallel with the device. The signal can be read out as $\mathrm{V} \mathrm{Hz}^{-1 / 2}$ from the frequency analyzer in the range of $\sim 10-1000 \mathrm{~Hz}$, and the corresponding current was calculated by dividing the resistance of the perovskite SCM. The incident intensity was measured using an Optical Power Meter (VEGA OPHIR PD300-UV) and calibrated with a silicon photodetector. All measurements were taken at room temperature.

Electron microscopy: SEM imaging was performed on a field-emission SEM (SU-8020, Hitachi). TEM and HRTEM imaging was conducted on a FEI Tecnai G2 F20.

Atomic force microscopy (AFM): AFM images were acquired on a Bruker Dimension ICON instrument.

Photography: Photographs in this manuscript were taken by using an eightmega-pixel digital camera.

\section{Data availability}

The data that support the plots within this Article and other findings of this study are available from the corresponding authors upon reasonable request.

Received: 22 August 2018 Accepted: 29 October 2018

Published online: 13 December 2018

\section{References}

1. Liu, Y. et al. Thinness- and shape-controlled growth for ultrathin singlecrystalline perovskite wafers for mass production of superior photoelectronic devices. Adv. Mater. 28, 9204-9209 (2016).

2. Liu, Y. et al. 20-mm-Large single-crystalline formamidinium-perovskite wafer for mass production of integrated photodetectors. Adv. Opt. Mater. 4, 1829-1837 (2016).

3. Liu, Y. et al. Two-inch-sized perovskite $\mathrm{CH}_{3} \mathrm{NH}_{3} \mathrm{PbX}_{3}(\mathrm{X}=\mathrm{Cl}, \mathrm{Br}, \mathrm{I})$ crystals: growth and characterization. Adv. Mater. 27, 5176-5183 (2015).

4. Zhang, F. et al. Perovskite $\mathrm{CH}_{3} \mathrm{NH}_{3} \mathrm{PbI}_{3-\mathrm{x}} \mathrm{Br}_{\mathrm{x}}$ single crystals with chargecarrier lifetimes exceeding $260 \mu$ s. ACS Appl. Mater. Interfaces 9, 14827-14832 (2017).

5. Shi, D. et al. Low trap-state density and long carrier diffusion in organolead trihalide perovskite single crystals. Science 347, 519-522 (2015).

6. Saidaminov, M. I. et al. High-quality bulk hybrid perovskite single crystals within minutes by inverse temperature crystallization. Nat. Commun. 6, 7586 (2015).
7. Dong, Q. et al. Electron-hole diffusion lengths $>175$ mum in solution-grown CH3NH3PbI3 single crystals. Science 347, 967-970 (2015).

8. Zhang, F., Yang, B., Li, Y., Deng, W. \& He, R. Extra long electron-hole diffusion lengths in $\mathrm{CH}_{3} \mathrm{NH}_{3} \mathrm{PbI}_{3-\mathrm{x}} \mathrm{Cl}_{\mathrm{x}}$ perovskite single crystals. J. Mater. Chem. C 5, 8431-8435 (2017).

9. Liu, Y., Yang, Z. \& Liu, S. Z. Recent progress in single-crystalline perovskite research including crystal preparation, property evaluation, and applications. Adv. Sci. 5, 1700471 (2018).

10. Nayak, P. K. et al. Mechanism for rapid growth of organic-inorganic halide perovskite crystals. Nat. Commun. 7, 13303 (2016).

11. Uribe, J. I., Ramirez, D., Osorio-Guillén, J. M., Osorio, J. \& Jaramillo, F. $\mathrm{CH}_{3} \mathrm{NH}_{3} \mathrm{CaI}_{3}$ perovskite: synthesis, characterization, and first-principles studies. J. Phys. Chem. C 120, 16393-16398 (2016).

12. Dang, Y. et al. Formation of hybrid perovskite tin iodide single crystals by topseeded solution growth. Angew. Chem. Int. Ed. 55, 3447-3450 (2016).

13. Yao, Z. et al. Local temperature reduction induced crystallization of $\mathrm{MASnI}_{3}$ and achieving a direct wafer production. RSC Adv. 7, 38155-38159 (2017).

14. Zhumekenov, A. A. et al. Formamidinium lead halide perovskite crystals with unprecedented long carrier dynamics and diffusion length. Acs Energy Lett. 1, 32-37 (2016)

15. Han, Q. et al. Single crystal formamidinium lead iodide $\left(\mathrm{FAPbI}_{3}\right)$ : insight into the structural, optical, and electrical properties. Adv. Mater. 28, 2253-2258 (2016).

16. Saidaminov, M. I., Abdelhady, A. L., Maculan, G. \& Bakr, O. M. Retrograde solubility of formamidinium and methylammonium lead halide perovskites enabling rapid single crystal growth. Chem. Commun. 51, 17658-17661 (2015).

17. Dang, Y. et al. Crystallographic investigations into properties of acentric hybrid perovskite single crystals $\mathrm{NH}\left(\mathrm{CH}_{3}\right)_{3} \mathrm{SnX}_{3}(\mathrm{X}=\mathrm{Cl}, \mathrm{Br})$. Chem. Mater. 28, 6968-6974 (2016)

18. Sakai, N. et al. Solution-processed cesium hexabromopalladate(IV), $\mathrm{Cs}_{2} \mathrm{PdBr}_{6}$ for optoelectronic applications. J. Am. Chem. Soc. 139, 6030-6033 (2017).

19. Slavney, A. H., Hu, T., Lindenberg, A. M. \& Karunadasa, H. I. A bismuthhalide double perovskite with long carrier recombination lifetime for photovoltaic applications. J. Am. Chem. Soc. 138, 2138-2141 (2016).

20. McClure, E. T., Ball, M. R., Windl, W. \& Woodward, P. M. $\mathrm{Cs}_{2} \mathrm{AgBiX}_{6}(\mathrm{X}=\mathrm{Br}$, $\mathrm{Cl}$ ): new visible light absorbing, lead-free halide perovskite semiconductors. Chem. Mater. 28, 1348-1354 (2016).

21. Dirin, D. N., Cherniukh, I., Yakunin, S., Shynkarenko, Y. \& Kovalenko, M. V Solution-grown $\mathrm{Cs} \mathrm{PbBr}_{3}$ perovskite single crystals for photon detection. Chem. Mater. 28, 8470-8474 (2016)

22. Song, J. et al. Ultralarge all-inorganic perovskite bulk single crystal for highperformance visible-infrared dual-modal photodetectors. Adv. Opt. Mater. 5, 1700157 (2017).

23. Stoumpos, C. C. et al. Crystal growth of the perovskite semiconductor $\mathrm{CsPbBr}_{3}$ : a new material for high-energy radiation detection. Cryst. Growth Des. 13, 2722-2727 (2013).

24. Saidaminov, M. I. et al. Inorganic lead halide perovskite single crystals: phaseselective low-temperature growth, carrier transport properties, and selfpowered photodetection. Adv. Opt. Mater. 5, 1600704 (2017).

25. Zhang, Y., Liu, Y., Li, Y., Yang, Z. \& Liu, S. Z. Perovskite $\mathrm{CH}_{3} \mathrm{NH}_{3} \mathrm{~Pb}\left(\mathrm{Br}_{\mathrm{x}} \mathrm{I}_{1-\mathrm{x}}\right)_{3}$ single crystals with controlled composition for fine-tuned bandgap towards optimized optoelectronic applications. J. Mater. Chem. C 4, 9172-9178 (2016).

26. Wei, $\mathrm{H}$. et al. Dopant compensation in alloyed $\mathrm{CH}_{3} \mathrm{NH}_{3} \mathrm{PbBr}_{3-\mathrm{x}} \mathrm{Cl}_{\mathrm{x}}$ perovskite single crystals for gamma-ray spectroscopy. Nat. Mater. 16, 826-833 (2017).

27. Miao, X. et al. Air-stable $\mathrm{CsPb}_{1-\mathrm{x}} \mathrm{Bi}_{\mathrm{x}} \mathrm{Br}_{3}(0 \leq \mathrm{x} \ll 1)$ perovskite crystals: optoelectronic and photostriction properties. J. Mater. Chem. C 5, 4931-4939 (2017).

28. Huang, $\mathrm{Y}$. et al. The intrinsic properties of $\mathrm{FA}_{(1-\mathrm{x})} \mathrm{MA}_{\mathrm{x}} \mathrm{PbI}_{3}$ perovskite single crystals. J. Mater. Chem. A 5, 8537-8544 (2017).

29. Zhang, T. et al. A facile solvothermal growth of single crystal mixed halide perovskite $\mathrm{CH}_{3} \mathrm{NH}_{3} \mathrm{~Pb}\left(\mathrm{Br}_{1-\mathrm{x}} \mathrm{Cl}_{\mathrm{x}}\right)_{3}$. Chem. Commun. 51, 7820-7823 (2015).

30. Liu, Y. et al. $120 \mathrm{~mm}$ Single-crystalline perovskite and wafers: towards viable applications. Sci. China Chem. 60, 1367-1376 (2017).

31. Cao, F. et al. Novel perovskite/ $/ \mathrm{TiO}_{2} / \mathrm{Si}$ trilayer heterojunctions for highperformance self-powered ultraviolet-visible-near infrared (UV-Vis-NIR) photodetectors. Nano Res. 11, 1722-1730 (2018).

32. Sun, H. et al. Self-powered, flexible, and solution-processable perovskite photodetector based on low-cost carbon cloth. Small 13, 1701042 (2017).

33. $\mathrm{Lu}, \mathrm{H}$. et al. A self-powered and stable all-perovskite photodetector-solar cell nanosystem. Adv. Funct. Mater. 26, 1296-1302 (2016).

34. Peng, W. et al. Solution-grown monocrystalline hybrid perovskite films for hole-transporter-free solar cells. Adv. Mater. 28, 3383-3390 (2016).

35. Rao, H. S., Chen, B. X., Wang, X. D., Kuang, D. B. \& Su, C. Y. A micron-scale laminar $\mathrm{MAPbBr}_{3}$ single crystal for an efficient and stable perovskite solar cell. Chem. Commun. 53, 5163-5166 (2017). 
36. Bao, C. et al. Low-noise and large-linear-dynamic-range photodetectors based on hybrid-perovskite thin-single-crystals. Adv. Mater. 29, 1703209 (2017).

37. Chen, Z. et al. Thin single crystal perovskite solar cells to harvest belowbandgap light absorption. Nat. Commun. 8, 1890 (2017).

38. Rao, H. S., Li, W. G., Chen, B. X., Kuang, D. B. \& Su, C. Y. In situ growth of $120 \mathrm{~cm}^{2} \mathrm{CH}_{3} \mathrm{NH}_{3} \mathrm{PbBr}_{3}$ perovskite crystal film on FTO glass for narrowbandphotodetectors. Adv. Mater. 29, 1602639 (2017).

39. Zhang, X. et al. Stable high efficiency two-dimensional perovskite solar cells via cesium doping. Energy Environ. Sci. 10, 2095-2102 (2017).

40. Thirumal, K. et al. Morphology-independent stable white-light emission from self-assembled two-dimensional perovskites driven by strong exciton-phonon coupling to the organic framework. Chem. Mater. 29, 3947-3953 (2017).

41. Ha, S. T., Shen, C., Zhang, J. \& Xiong, Q. Laser cooling of organic-inorganic lead halide perovskites. Nat. Photon. 10, 115-121 (2015).

42. Gauthron, K. et al. Optical spectroscopy of two-dimensional layered $\left(\mathrm{C}_{6} \mathrm{H}_{5} \mathrm{C}_{2} \mathrm{H}_{4} \mathrm{NH}_{3}\right)_{2} \mathrm{PbI}_{4}$ perovskite. Opt. Express 18, 5912-5919 (2010).

43. Mitzi, D. B. A layered solution crystal growth technique and the crystal structure of $\left(\mathrm{C}_{6} \mathrm{H}_{5} \mathrm{C}_{2} \mathrm{H}_{4} \mathrm{NH}_{3}\right)_{2} \mathrm{PbCl}_{4}$. J. Solid State Chem. 145, 694-704 (1999).

44. Kagan, C. R. Organic-inorganic hybrid materials as semiconducting channels in thin-film field-effect transistors. Science 286, 945-947 (1999).

45. Liang, K., Mitzi, D. B. \& Prikas, M. T. Synthesis and characterization of organic-inorganic perovskite thin films prepared using a versatile two-step dipping technique. Chem. Mater. 10, 403-411 (1998).

46. Era, M., Morimoto, S., Tsutsui, T. \& Saito, S. Organic-inorganic heterostructure electroluminescent device using a layered perovskite semiconductor $\left(\mathrm{C}_{6} \mathrm{H}_{5} \mathrm{C}_{2} \mathrm{H}_{4} \mathrm{NH}_{3}\right)_{2} \mathrm{PbI}_{4}$. Appl. Phys. Lett. 65, 676-678 (1994).

47. Dammak, $\mathrm{T}$. et al. Two-dimensional excitons and photoluminescence properties of the organic/inorganic $\left(4-\mathrm{FC}_{6} \mathrm{H}_{4} \mathrm{C}_{2} \mathrm{H}_{4} \mathrm{NH}_{3}\right)_{2}\left[\mathrm{PbI}_{4}\right]$ nanomaterial. J. Phys. Chem. C 113, 19305-19309 (2009).

48. Kitazawa, $\mathrm{N}$. Optical absorption and photoluminescence properties of $\mathrm{Pb}(\mathrm{I}$, Br)-based two-dimensional layered perovskite. Jpn. J. Appl. Phys. 36, 2272-2276 (1997).

49. Kitazawa, N. Excitons in two-dimensional layered perovskite compounds: $\left(\mathrm{C}_{6} \mathrm{H}_{5} \mathrm{C}_{2} \mathrm{NH}_{3}\right)_{2} \mathrm{H}_{4} \mathrm{~Pb}(\mathrm{Br}, \mathrm{I})_{4}$ and $\left(\mathrm{C}_{6} \mathrm{H}_{5} \mathrm{C}_{2} \mathrm{NH}_{3} \mathrm{~Pb}(\mathrm{Cl}, \mathrm{Br})_{4}\right.$. Mater. Sci. Eng. $B$ 49, 233-238 (1997).

50. Kikuchi, K., Takeoka, Y., Rikukawa, M. \& Sanui, K. Structure and optical properties of lead iodide based two-dimensional perovskite compounds containing fluorophenethylamines. Curr. Appl. Phys. 4, 599-602 (2004).

51. Saidaminov, M. I., Mohammed, O. F. \& Bakr, O. M. Low-dimensionalnetworked metal halide perovskites: the next big thing. ACS Energy Lett. 2, 889-896 (2017).

52. Shimizu, M., Fujisawa, Ji \& Ishihara, T. Photoluminescence of the inorganicorganic layered semiconductor $\left(\mathrm{C}_{6} \mathrm{H}_{5} \mathrm{C}_{2} \mathrm{H}_{4} \mathrm{NH}_{3}\right)_{2} \mathrm{PbI}_{4}$ : observation of triexciton formation. Phys. Rev. B 74, 155206 (2006).

53. Peng, W. et al. Ultralow self-doping in two-dimensional hybrid perovskite single crystals. Nano. Lett. 17, 4759-4767 (2017).

54. Liu, W. et al. Giant two-photon absorption and its saturation in 2D organicinorganic perovskite. Adv. Opt. Mater. 5, 1601045 (2017).

55. Lédée, F. et al. Fast growth of monocrystalline thin films of $2 \mathrm{D}$ layered hybrid perovskite. CrystEngComm 19, 2598-2602 (2017).

56. Dou, L. et al. Solution-processed hybrid perovskite photodetectors with high detectivity. Nat. Commun. 5, 5404 (2014).

57. Gong, X. et al. High-detectivity polymer photodetectors with spectral response from $300 \mathrm{~nm}$ to $1450 \mathrm{~nm}$. Science 325, 1665-1667 (2009).

58. Ghadi, H. et al. Enhancement in peak detectivity and operating temperature of strain-coupled InAs/GaAs quantum dot infrared photodetectors by rapid thermal annealing. IEEE Trans. Nanotechnol. 14, 668-672 (2015).

59. Wei, H., Fang, Y., Yuan, Y., Shen, L. \& Huang, J. Trap engineering of CdTe nanoparticle for high gain, fast response, and low noise P3HT:CdTe nanocomposite photodetectors. Adv. Mater. 27, 4975-4981 (2015).

60. Gundimeda, A. et al. Fabrication of non-polar GaN based highly responsive and fast UV photodetector. Appl. Phys. Lett. 110, 103507 (2017).

61. Dang, Y. Y. et al. Bulk crystal growth of hybrid perovskite material $\mathrm{CH}_{3} \mathrm{NH}_{3} \mathrm{PbI}_{3}$. CrystEngComm 17, 665-670 (2015).

62. Nernst, W. Theorie der reaktionsgeschwindigkeit in heterogenen systemen. $Z$. Phys. Chem. 47, 52-55 (1904).

63. Dash, J. G. Clustering and percolation transitions in helium and other thin films. Phys. Rev. B 15, 3136-3146 (1977).
64. Sung, M. H., Kim, J. S., Kim, W. S., Hirasawa, I. \& Kim, W. S. Modification of crystal growth mechanism of yttrium oxalate in metastable solution. J. Cryst. Growth 235, 529-540 (2002).

65. Zhang, N. H. \& Xing, J. J. An alternative model for elastic bending deformation of multilayered beams. J. Appl. Phys. 100, 103519 (2006).

66. Li, J. B. et al. Solution coating of superior large-area flexible perovskite thin films with controlled crystal packing. Adv. Opt. Mater. 5, 1700102 (2017).

67. Edri, E. Elucidating the charge carrier separation mechanism in $\mathrm{CH}_{3} \mathrm{NH}_{3} \mathrm{PbI}_{3}$ ${ }_{\mathrm{x}} \mathrm{Cl}_{\mathrm{x}}$ perovskite solar cells. Nat. Commun. 5, 3461 (2014).

68. Konstantatos, G., Clifford, J., Levina, L. \& Sargent, E. H. Sensitive solutionprocessed visible-wavelength photodetectors. Nat. Photon. 1, 531-534 (2007).

69. Pan, W. et al. $\mathrm{Cs}_{2} \mathrm{AgBiBr}_{6}$ single-crystal X-ray detectors with a low detection limit. Nat. Photon. 11, 726-732 (2017).

70. Fang, Y. J., Dong, Q. F., Shao, Y. C., Yuan, Y. B. \& Huang, J. S. Highly narrowband perovskite single-crystal photodetectors enabled by surfacecharge recombination. Nat. Photon. 9, 679-687 (2015).

\section{Acknowledgements}

This work was funded by the National Key Research and Development Program of China (2017YFA0204800), the Fundamental Research Funds for the Central Universities (2018CBLZ006), National Natural Science Foundation of China (91733301, 61604092 and 61674098), the 111 Project (B14041), the Changjiang Scholar and Innovative Research Team (IRT_14R33), the Natural Science Basic Research Plan in Shaanxi Province of China (2018JM5132), and the Fundamental Research Funds for the Central Universities (GK201803012).

\section{Author contributions}

S.(F.)L., K.Z. and Y.L. proposed the project. Y.L. and Y.Z. synthesized the sample and fabricated the devices. Y.L., Z.Y., J.L., L.M., K.W., P.Z., Q.L., M.H., H.X., Z.Y. and G.Z. carried out the material characterizations. D.-M.S., R.M., and A.A. carried out grazingincidence wide-angle X-ray scattering measurements. Y.L., Y.Z., Z.Y., H.Y., X.Z., J.L. and J.F. carried out the photosensor measurements. Z.X. performed the simulations. Y.L., Y.Z., and Z.Y. analyzed all experimental data. Y.L., K.Z. and S.(F.)L. wrote the manuscript with discussion and input from all the authors.

\section{Additional information}

Supplementary Information accompanies this paper at https://doi.org/10.1038/s41467018-07440-2.

Competing interests: The authors declare no competing interests.

Reprints and permission information is available online at http://npg.nature.com/ reprintsandpermissions/

Publisher's note: Springer Nature remains neutral with regard to jurisdictional claims in published maps and institutional affiliations.

Open Access This article is licensed under a Creative Commons Attribution 4.0 International License, which permits use, sharing, adaptation, distribution and reproduction in any medium or format, as long as you give appropriate credit to the original author(s) and the source, provide a link to the Creative Commons license, and indicate if changes were made. The images or other third party material in this article are included in the article's Creative Commons license, unless indicated otherwise in a credit line to the material. If material is not included in the article's Creative Commons license and your intended use is not permitted by statutory regulation or exceeds the permitted use, you will need to obtain permission directly from the copyright holder. To view a copy of this license, visit http://creativecommons.org/ licenses/by/4.0\%.

(C) The Author(s) 2018 